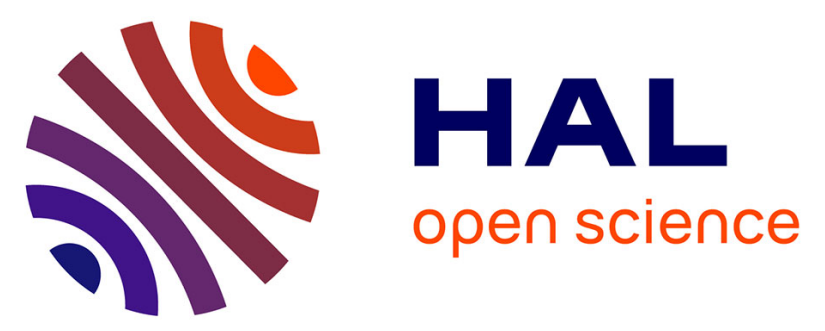

\title{
Are subsidies to weather-index insurance the best use of public funds? A bio-economic farm model applied to the Senegalese groundnut basin
}

\author{
Aymeric Ricome, François Affholder, Françoise Gérard, Bertrand Muller, \\ Charlotte Poeydebat, Philippe Quirion, Moussa Sall
}

\section{To cite this version:}

Aymeric Ricome, François Affholder, Françoise Gérard, Bertrand Muller, Charlotte Poeydebat, et al.. Are subsidies to weather-index insurance the best use of public funds? A bio-economic farm model applied to the Senegalese groundnut basin. Agricultural Systems, 2017, 156, pp.149 - 176. 10.1016/j.agsy.2017.05.015 . hal-01679763

\section{HAL Id: hal-01679763 https://hal.science/hal-01679763}

Submitted on 23 May 2018

HAL is a multi-disciplinary open access archive for the deposit and dissemination of scientific research documents, whether they are published or not. The documents may come from teaching and research institutions in France or abroad, or from public or private research centers.
L'archive ouverte pluridisciplinaire HAL, est destinée au dépôt et à la diffusion de documents scientifiques de niveau recherche, publiés ou non, émanant des établissements d'enseignement et de recherche français ou étrangers, des laboratoires publics ou privés. 


\title{
Are subsidies to weather-index insurance the best use of public funds?
}

\section{A bio-economic farm model applied to the Senegalese groundnut basin}

\author{
Aymeric Ricome, François Affholder, Françoise Gérard, Bertrand Muller,
} Charlotte Poeydebat, Philippe Quirion, Moussa Sall.

Aymeric Ricome : IRD, Centre International de Recherche sur l'Environnement et le Développement (CIRED), F-94736 Nogent sur Marne, France. The author works now at the European Commission, Joint Research Center.

François Affholder: Centre International de Recherche Agronomique pour le Développement (CIRAD), UPR AIDA, F-34398 Montpellier, France.

Françoise Gérard : CIRAD, UPR GREEN, F-94736 Nogent sur Marne, France.

Bertrand Muller : CIRAD, UMR AGAP, F-34398 Montpellier, France, and Centre d'étude régional pour l'amélioration de l'adaptation à la sécheresse (CERAAS), Thiès, Sénégal.

Charlotte Poeydebat : CIRAD, UPR AIDA, F-34398 Montpellier, France.

Philippe Quirion : CNRS, Centre International de Recherche sur l'Environnement et le Développement (CIRED), F-94736 Nogent sur Marne, France.

Moussa Sall : Institut Sénégalais de Recherche Agricole (ISRA), Dakar, Sénégal. 


\section{Are subsidies to weather-index insurance the best use of public funds?}

A bio-economic farm model applied to the Senegalese groundnut basin

\section{Keywords}

index insurance; drought insurance; Senegal; crop intensification

\section{Highlights}

- We developed a coupled crop-farm simulation model for semi-arid West Africa.

- We assessed the soundness at farm scale of policies supporting cereal intensification.

- Weather-index insurance reduces risks and increases expected income only for certain farms.

- Subsidies to credit or unconditional cash-transfers increase expected income and production more than subsidies to insurance.

- Unsubsidized insurance combined with subsidized credit best favor cereal intensification.

\section{Abstract}

While crop yields in Sub-Saharan Africa are low compared to most other parts of the world, weather-index insurance is often presented as a promising tool, which could help resource-poor farmers in developing countries to invest and adopt yield-enhancing technologies. Here, we test this hypothesis on two contrasting areas (in terms of rainfall scarcity) of the Senegalese groundnut basin through the use of a bio-economic farm model, coupling the crop growth model CELSIUS with the economic model ANDERS, both specifically designed for this purpose. We introduce a weather-index insurance whose index is currently being used for pilot projects in Senegal and West Africa. Results show that insurance leads to a welfare gain only for those farmers located in the driest area. These farmers respond to insurance mostly by increasing the amount of cow fattening, which leads to higher crop yields thanks to the larger production of manure. We also find that subsidizing insurance is not the best possible use of public funds: for a given level of public funding, reducing credit rates, subsidizing fertilizers, or just transferring cash as a lump-sum generally brings a higher expected utility to farmers and leads to a higher increase in grain production levels. 


\section{Introduction}

In west African countries, agricultural production per capita has decreased over the past half century due to a slow increase in agricultural production compared to the rate of population growth (Pretty et al., 2011). With continued population growth and the diminishing availability of marginal arable land, there is now a common view that crop yield must increase in this region, especially as there is a wide gap between actual and potential yields (World Bank, 2008; HLPE, 2013; Teklewold et al., 2013; The Montpellier Panel, 2013). At field scale, low nutrient availability in soils and high weed pressure predominantly explain this yield gap (Affholder et al., 2013). At farm level, the fact that households are strongly resource-constrained and exposed to risk is widely recognized as a key explanation (Rosenzweig, 1993; Carter and Barrett, 2006). Indeed, risk discourages the adoption of high-risk, high-return agricultural technologies, especially when farmers are poor, which in turn impedes the improvement of yields (Affholder, 1997).

This is the reason why, for over a decade, weather-index insurance (WII) have been seen as a promising tool to mitigate agro-climatic risks at farm level and thus in the improvement of yields (Hazell and Hess, 2010). Here we define WII as insurance whose indemnities are triggered by the value of a weather index chosen for its high correlation with yields or economic losses. As WII do not require loss assessment as in conventional insurance, transaction costs are lower. Additionally, the use of an objective indicator prevents information asymmetries among contractors, while with conventional insurance based on yield loss, the insurer cannot always determine to what extent the loss is due to a bad weather or to farmer's lack of work.

Despite the allocation of many resources by international development organizations, results from pilot WII programs showed up to a recent period very limited success. Binswanger-Mkhize (2012) explained it by the lack of demand. While better-off farmers prefer to use cheaper selfinsurance strategies rather than WII, poor farmers would be interested but could not afford it because of lack of liquidity.

Ex-post analysis confirmed this argument by highlighting several factors explaining the low take-up of WII: steep negative price elasticity (Karlan et al., 2014; Cole et al., 2013; Mobarak and Rosenzweig, 2013), liquidity constraints (Cole et al., 2013), lack of trust and misunderstanding of the products (Hill et al., 2013), lack of relevant social networks (Giné et al., 2013) and existence of informal insurance which acts as a substitute (Mobarak and Rosenzweig, 2013). Another key limitation of WII is the basis risk i.e. the imperfect correlation between the index and losses at farm level (Tadesse et al., 2015). 
Ex-ante assessments do not provide more optimistic conclusions. Mclntosh et al. (2013) compared an ex-ante WTP for WII with ex-post demand based on an actual WII in Ethiopia. They found that the lack of cash (and access to credit) to pay for the WII product reduced the interest of farmers and that subsidizing premium improved the take-up of insurance but not as much as expected.

Other ex-ante assessments are based on agro-economic simulation models. Berg et al. (2009) and Leblois et al. (2014) found that the benefits of insurance were very limited for, respectively, maize growers in Burkina Faso and cotton growers in Cameroon. These results were explained by the large basis risk and, in the case of cotton, the higher exposure of farmers to price risk than to climatic risk.

Aware of these drawbacks, new programs were developed and seem scaling up and providing demonstrable benefits for a larger number of farmers, even if in a lower extent to poorest ones (Greatrex et al., 2015; Bertram-Huemmer \& Kraehnert, 2015). The experiences in India, Kenya, Ethiopia and Mongolia innovated by linking insurance to credit or improved inputs, involved the farmers into the product design and were encompassed into a strong institutional setting favoring trust between farmers and insurers as well as improving the understanding of the products. It appears from those programs that when the WII is included in a larger basket of risk management options, the benefits of the programs are larger.

Although these studies and experiences are helpful to know the factors influencing the adoption of WII by farmers, knowledge of the impacts of WII on farmers' production decisions is still very limited: while De Nicola (2015), Elabed and Carter (2014), Karlan et al. (2014) and Mobarak and Rosenzweig (2013) provide evidence that WII can boost adoption of new technologies, Giné and Yang (2009) come to the opposite conclusion. Carter et al. (2016) have shown in a theoretical model that whether WII may or not boost the adoption of improved agricultural technologies depends in particular on the agro-ecological and economic environments, which calls for more applied work on this issue.

The objective of this paper is thus to evaluate the potential benefit from WII in terms of farmers' income and its impact on adoption of more intensive cropping and livestock systems. We write "potential" because our model represents simulated farmers who would be perfectly aware of the way WII works. We also assess whether insurance subsidies are the best use of public funds by comparing this policy option with others such as credit subsidies, fertilizer subsidies or lump-sum cash transfers, considered separately or in conjunction with WII. We develop a coupled whole-farm bio-economic model (Janssen and van Ittersum, 2007; Le Gal et al, 2011), reproducing the complexity 
of farmers' decisions in a risky environment, applied to typical farms in the Senegalese groundnut basin. The model explicitly represents the cropping and livestock systems, with a biophysical component simulating the impact on crop yields of changes in crop management techniques and of inter-annual variations of climate, as well as the various nutritional, financial and labor management constraints of the household. The coupled model simulates farm households' decisions in response to a series of historical weather data, which are assumed to represent the perception of the interannual variability of weather. Furthermore, we characterize the diversity of the farming systems in the study areas in order to account for possible differences between farm-types regarding the relevance and impacts of WII.

\section{Material and methods}

The analysis took place in the "groundnut basin" of Senegal. It is a region typical in many aspects of the Sudano-Sahelian region of Africa, with high levels of poverty, where family farming based on rainfed crops is overwhelmingly predominant, with a semi-arid climate, and with a steep South-North gradient of risks of drought limiting crop production (Boulier and Jouve, 1990). A consistent background was available about the farming systems of that region and their dependencies to both the biophysical and the socio economic environment of farms, thanks to many studies at field, farm and village scales that were carried out at regular time intervals in the past (Lericollais, 1972; Benoit-Cattin, 1986; Lhoste, 1986; Pieri, 1989; Boulier and Jouve, 1990; Garin et al., 1990; Badiane et al., 2000a; ISRA, 2008). However, a new survey was carried out within the framework of the present study at field and farm levels in order to get adequately updated data for the specific purpose of developing and calibrating our whole-farm model.

\subsection{General presentation of the study area}

We considered two subzones in the study area, the districts of Niakhar $\left(14^{\circ} 28^{\prime} \mathrm{N}, 16^{\circ} 24^{\prime} \mathrm{W}, 25\right.$ km South of Bambey on Figure 1) and Nioro du Rip $\left(13^{\circ} 44^{\prime} \mathrm{N}, 15^{\circ} 46^{\prime} \mathrm{W}\right)$, respectively in the center north (locally known as the Sine region) and in the south of the groundnut basin (Saloum), corresponding to contrasting drought risk, expected to lead to contrasting constraints on crop intensification (Affholder, 1997). The average annual cumulative rainfall recorded during the period considered in this study (1991-2010) is $520 \mathrm{~mm}$ and $775 \mathrm{~mm}$ in Sine and Saloum respectively.

Throughout the basin the cropping systems are mainly cereal-leguminous rotations. In the Sine subzone the cereal used in the rotation is almost exclusively millet (the staple food) and the use of mineral fertilizers is extremely rare. Horses and donkeys provide traction power for carts as well as for sowing and weeding machines. In Saloum maize, grown as a cash crop or staple food, is common 
although millet remains the main cereal. Manure is more widely employed than in Sine. Traction power is provided by horses (carts) and oxen (cultivation tools). In both zones farmers also carry out very extensive cattle production and slightly more intensive breeding of a few small ruminants (sheep and goats), and in many cases a short-term fattening activity involving a few cattle or small ruminants. All this livestock activities provide manure that is used in several ways for organic fertilization of fields. Very few mineral fertilizers or pesticides are used. No improved seeds are available for millet. Groundnut seeds are all improved seeds produced and distributed under the control of public services. An important feature of the farming system is the ring cultivation system which involves dividing the landscape into two concentric circular areas around the household's compounds. The area closer to the compounds, the "home-fields", is under continuous cereal cropping and receives all of the household's organic waste, as opposed to the bush-fields, which are far from the compounds and where cereals alternate with groundnut. Crop yields obtained on homefields are thus generally higher thanks to the higher levels of soil organic matter (Prudencio, 1993).

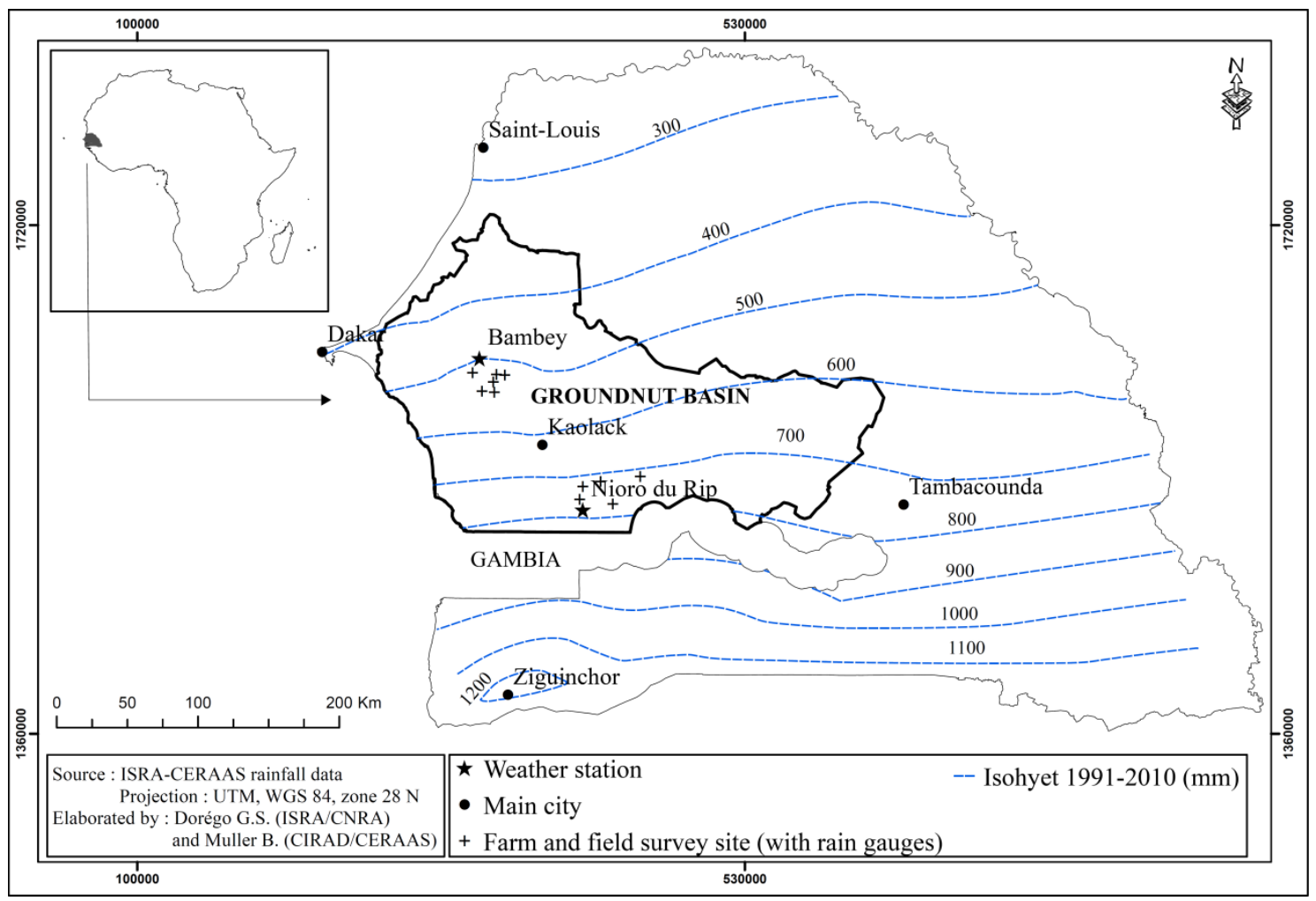

Figure 1: Study area and rainfall levels in Senegal over the period 1991-2010 


\subsection{Data}

The dataset comprises socio demographic and economic data from a farm household survey conducted in 2012. Local experts identified five representative villages for each study subzone, in which 18 households were randomly selected. 180 households were surveyed overall. The structured questionnaire included questions on household structure (composition, ages, gender, etc.), detailed land, capital (seeder, plow, etc.), and livestock (cattle, horses, sheep, etc.) holdings, sociodemographic characteristics of the family, numbers of migrants, financial and credit constraints, crop and livestock systems management and performance (labor requirements, input prices, etc.).

Data on local monthly output prices over 1996-2011 were obtained from the Senegalese Economics and Statistics Administration (DAPS).

Biophysical and technical data describing the field management practices were collected in 2013 from 206 fields (134 in Sine and 72 in Saloum) belonging to 40 households selected from the previous sample ( 20 households per subzone) using a proportionate random sampling based on farm typologies built up from the farm household survey and presented below. The structured plot level questionnaire aimed to gather data on soil characteristics, details of crop management (cultivar chosen, sowing date, plant density, amounts of inorganic and organic fertilizers used, weeding sequence, etc.), and decision rules related to the sowing date.

The data used for calibration of the biophysical component of the model were extracted from the ESPACE-PRODCLIM (Forest and Cortier, 1989; Baron, 1991) and AMMA databases (Kouakou, 2013), built from surveys among farmers' fields and trials in the study area carried out in 1990-1992 and 2006-2008, respectively. Overall, the merged database consisted of 959 plot-year observations of c. $25 \mathrm{~m}^{2}$ delineated within fields, allowing comparisons between observed and simulated values of grain and biomass yields under a large range soils, rainfall intra-annual distributions, and management techniques. Organic $\mathrm{N}$ in soils was taken as constant for each soil type in each cultivation ring, using estimates from Badiane et al. (2000b). N contents in manure from the various sources used in the region were taken from Fall et al. (2000). Historical series of climate data for yield simulations were those available from the two main stations of this network, namely the weather stations of Bambey $\left(14^{\circ} 41^{\prime} \mathrm{N}, 16^{\circ} 24^{\prime} \mathrm{W}\right)$ and Nioro du Rip $\left(13^{\circ} 44^{\prime} \mathrm{N}, 15^{\circ} 46^{\prime} \mathrm{W}\right)$, respectively assumed to represent the current climate of the Sine and Saloum subzones. Both climatic datasets cover 19502010 and include daily values of rainfall, temperatures, relative humidity, wind speed and sunshine duration (used to estimate solar radiation). 


\subsection{Farm-types}

Farm diversity had to be characterized since insurance may be appropriate for some farmers but inadequate for others due to variations among farms in the nature and importance of the risks faced. For each subzone we built a farm typology reflecting the resource access and the needs of the family, following the livelihoods approach (Bebbington, 1999). Individual farms were grouped into farm-types by using an Agglomerative Hierarchical Clustering (AHC) method consisting of progressively grouping farm households according to their degree of resemblance. In accordance with common practice (e.g. Blazy et al., 2009) we used Euclidean distance as the measure of distance between pairs of observations, and the Ward Criterion as the linkage algorithm. It appeared that the 6 variables capturing the best the farm heterogeneity were related to farm resources and needs: total farm land area, number of persons making up the household, area per worker, herd size, number of draught animals and number of migrants (see Appendix $A$ for details on the method and characteristic of farm-types). 
Table 1 Characteristics of the farm-types ${ }^{1}$

\begin{tabular}{|c|c|c|c|c|c|c|c|c|}
\hline \multirow{2}{*}{$\begin{array}{l}\text { Variable } \\
\text { category }\end{array}$} & \multirow[t]{2}{*}{ Variable } & \multirow[t]{2}{*}{ Definition } & \multicolumn{2}{|c|}{ Type 1} & \multicolumn{2}{|c|}{ Type 2} & \multicolumn{2}{|c|}{ Type 3} \\
\hline & & & Sine1 & Saloum1 & Sine2 & Saloum2 & Sine3 & Saloum3 \\
\hline & Region & Share of the farm-type on the subzone & $62 \%$ & $83 \%$ & $13 \%$ & $13 \%$ & $25 \%$ & $4 \%$ \\
\hline \multirow{4}{*}{$\begin{array}{l}\frac{\text { Household }}{\text { structure and }} \\
\text { migration: }\end{array}$} & Pers & Total number of persons in the households & $11.7^{* * *}$ & $15.1 * * *$ & $17^{* * *}$ & $19.91 * * *$ & $20.3^{* * *}$ & $25.3 * * *$ \\
\hline & Labor & Number of workers & $4.5^{* * *}$ & $5 * * *$ & $7 * * *$ & $8 * * *$ & $9 * * *$ & $10 * * *$ \\
\hline & OffFarm & Number of persons working off farm & $0.29 * * *$ & 0.56 & $0.9 * * *$ & 0.75 & $1.32^{* * *}$ & 0.66 \\
\hline & Migr & Number of migrants & $1.4^{* *}$ & 1.27 & $2^{* *}$ & 1.66 & $0.73 * *$ & 1 \\
\hline \multirow{3}{*}{$\begin{array}{l}\text { Land } \\
\text { endowment: }\end{array}$} & Area & Total farm land area (ha) & $3.5^{* * *}$ & $6.5^{* * *}$ & $10.5^{* * *}$ & $15.2 * * *$ & $7.75^{* * *}$ & $11.1^{* * *}$ \\
\hline & HomeField & $\%$ homefield & 0.27 & 0.06 & 0.3 & 0.03 & $0.18^{* *}$ & 0.16 \\
\hline & BushField & $\%$ bushfield & 0.73 & 0.94 & 0.7 & 0.97 & $0.82^{* *}$ & 0.84 \\
\hline \multirow{3}{*}{$\begin{array}{l}\text { Capital } \\
\text { endowment: }\end{array}$} & RatioWeedSurf & Number of weeding tools per ha & $1.65^{* * *}$ & 0.79 & $0.66 * * *$ & 0.61 & $1.38^{* * *}$ & 0.85 \\
\hline & RatioHoeSurf & Number of seeders, hoe per ha & $0.67 * *$ & 0.47 & 0.37 & 0.35 & 0.34 & 0.57 \\
\hline & Cart & Number of handcart per ha & $0.35 * * *$ & 0.11 & $0.13 * * *$ & 0.08 & $0.2^{* * *}$ & 0.18 \\
\hline \multirow{3}{*}{$\begin{array}{l}\text { Cash and } \\
\text { credit access: }\end{array}$} & Cash & Cash level in the farm household per worker (FCFA) & 17000 & 18500 & 40000 & 18000 & 65000 & 70000 \\
\hline & Credit & Dummy variable: 1 if the farmer gets a credit & 0.34 & $0.4^{* *}$ & 0.54 & $0.5^{* *}$ & 0.55 & $1 * *$ \\
\hline & Cattle & Head of cattle & 1 & 0.56 & 1 & $0.75^{*}$ & $17.1^{* * *}$ & $25 * * *$ \\
\hline \multirow{4}{*}{$\begin{array}{l}\text { Livestock } \\
\text { systems: }\end{array}$} & DraftAni & Head of draught animal & 2.1 & $0.57 * * *$ & 2.9 & $5.08 * * *$ & $3.54^{* *}$ & $8.66 * * *$ \\
\hline & CowFat & Head of cow fattening & $0.56 * * *$ & 0 & $1.9 * * *$ & 0 & $6 * * *$ & 0 \\
\hline & Sheep & Head of sheep & $11.7 * * *$ & $6.65 * * *$ & $22.3 * * *$ & $9.3 * * *$ & $25^{* * *}$ & $35^{* * *}$ \\
\hline & SheepFat & Head of sheep fattening & 3.27 & 0.12 & 5 & 0.16 & 6.3 & $2 * * *$ \\
\hline \multirow{5}{*}{$\begin{array}{l}\text { Cropping } \\
\text { systems: }\end{array}$} & Manure & Dummy variable $: 1$ if manure is used on farm & 0.95 & $0.68^{* *}$ & 1 & 1 & 1 & 1 \\
\hline & Fertilizer & Dummy variable : 1 if fertilizer is used on farm & 0.42 & 0.8 & 0.45 & 0.9 & 0.67 & 1 \\
\hline & Millet & Share of the land dedicated to pearl millet & 0.55 & $0.57^{*}$ & 0.53 & $0.49 *$ & 0.5 & $0.36^{*}$ \\
\hline & Maize & Share of the land dedicated to maize & 0.02 & $0.09 *$ & 0 & $0.14^{*}$ & 0 & $0.23 * *$ \\
\hline & Groundnut & Share of the land dedicated to groundnut & 0.43 & 0.33 & 0.47 & 0.36 & 0.5 & 0.41 \\
\hline
\end{tabular}

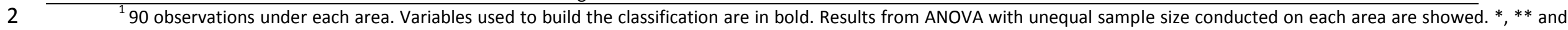
$3 * * *$ indicate statistically significant differences between groups at $10 \%, 5 \%$ and $1 \%$ level respectively. 
A similar picture appears in the two subzones: two farm-types are characterized by a mixed crop-livestock farming system and represent $75 \%$ and $96 \%$ of the farms in the Sine and Saloum subzone, respectively. The remaining households constitute a third type, oriented almost exclusively toward livestock systems (see Table 1). It was excluded from the analysis for three reasons: (i) its low representativeness, (ii) the absence of insurance contract for livestock in the region; (iii) the inability of the model designed (yearly planning horizon) to properly predict significant changes in the size of extensive livestock in such farms, whereas short-term animal fattening activities of other farm types were accounted for in the model.

Type 1 are the most numerous and the poorest: in Sine1 the average yearly income including self-consumption is only 660 000CFA $(1003 €)$ for approximately 12 people of which 4.5 workers, while in Saloum1 it amounts to 835000 CFA (1269€) for approximately 15 people of which 5 workers. Thus the income per worker is far below the poverty line of 225000 CFA (343€; BCEAO, 2012), and the income per capita is even further away. The land constraint is heavy with farm area of only 3.5 and 6.5 ha in Sine1 and Saloum 1 respectively. This type is mainly oriented toward selfconsumption and heavily constrained by its lack of liquidity. Access to credit is very limited. Consequently, the use of external inputs is very low and the proportion of land dedicated to millet is higher than for the other types. They also have very few head of livestock.

Type 2 are better off but still far below the poverty line when the dependents are considered, with an income of 1910000 CFA (2 903€) and 1800000 (2 736€) for approximately 17 and 20 people in Sine2 and Saloum2 respectively. It includes the farms with the highest land holding (10.5 and 15.2 ha) and labor is the main constraint. As for type 1, they own very few head of livestock but animal fattening, a risky but profitable activity, is slightly larger. The access to credit is higher and they use more fertilizer than type 1.

\subsection{The bio-economic model}

The bio-economic ANDERS-CELSIUS model was designed to simulate the choices of farmers characterized by a mixed crop-livestock farming system, especially their crop choice, crop management strategy (manure, fertilizer), animal production strategy (uniquely short-term animal fattening), consumption, credit and insurance decisions. The model accounts for price and yield risks and includes policies targeted at favouring crop intensification, defined in this paper as the increase in yield through a change in the crop's technical management. It was designed by developing and coupling two models (Figure 2): a dynamic crop model named CELSIUS (CEreal and Legume crops SImulator Under changing Sahelian environment) and a multi-periodic, 1-year-planning horizon farm household model, named ANDERS (Agricultural aNd Development Economics model for the 
gRoundnut basin in Senegal). CELSIUS simulates crop development, growth and biomass and grain

2 yields of a set of typical cropping systems under a 20-year series of historical climate data in order to

3 account for yield variability induced by inter-annual climate variations. As ANDERS is a 1-year model,

4 it takes the 20 yields provided by CELSIUS (proxy for the yield distribution) as equiprobable states of

5 nature that could occur during the simulated year with an equal probability.

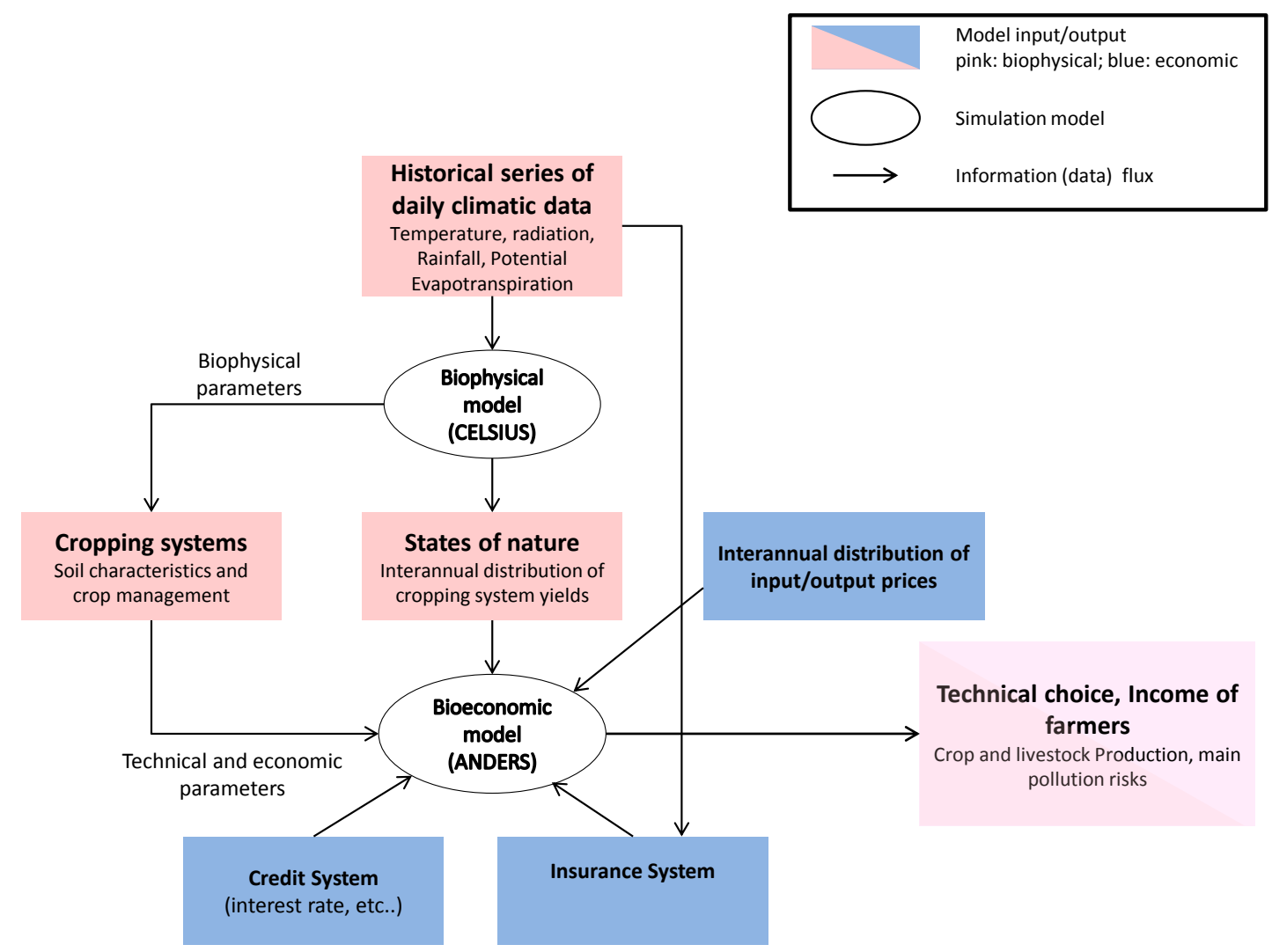

Figure 2. General flow chart of the coupled model ANDERS ("bioeconomic model") - CELSIUS

(“biophysical model”)

\subsubsection{Crop yield simulations with CELSIUS}

CELSIUS was used to provide inter-annual distributions of grain yields and of above-ground biomass yields, for a set of typical cropping systems. The cropping systems differ by the cultivar used and its grain and biomass potential yields, the sowing density, and the fertilization practice mobilizing organic and inorganic fertilizers (Table 2). Currently practiced cropping systems may be 'extensive' i.e. without any organic or inorganic fertilization, or 'intensive', i.e. with at least fertilization as a way to obtain higher yields than in the latter case. In the case of cereal crops whose yield are currently far below the potential permitted by rainfall (Affholder et al., 2013), the typical cropping systems we 

system and field type, the average yield and its coefficient of variation is presented in Appendix B.

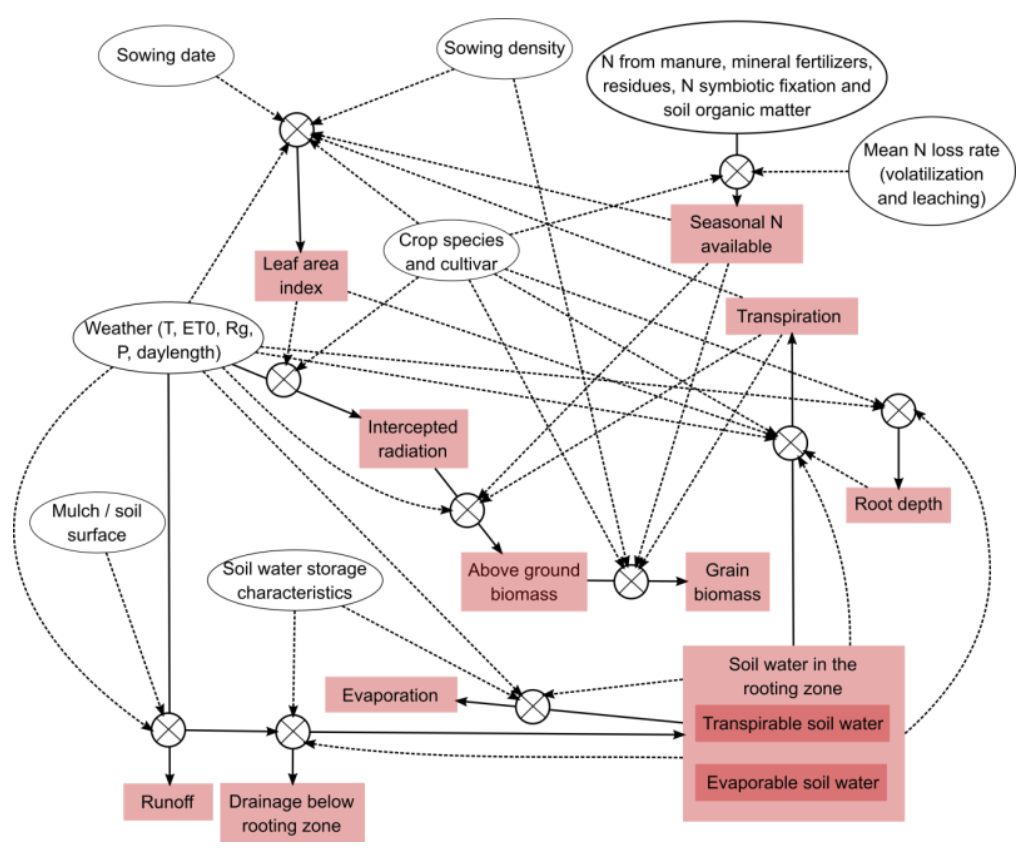

Figure 3. Flow chart of CELSIUS

CELSIUS is a simple dynamic crop model working on a daily time step, based on the concept of a potential yield limited by water and nitrogen stresses (Fig. 3). It was built in Visual Basic and integrated into a database in order to facilitate virtual experimentation and coupling with the farm model (Affholder et al., 2012). We tailored the model to its specific use in the study, re-using existing robust model components and keeping the complexity of the model and its resulting data requirements for parameterization as low as possible (Sinclair and Seligman, 1996; Sinclair and Seligman, 2000; Affholder et al., 2012). CELSIUS was adapted from a previously published model (Potential Yield Estimator, PYE) in Affholder et al. (2013) which uses formalisms that had proven to be valid across a wide range of environments and crops to simulate the water-limited yield of annual crops, $\mathrm{Yw}$, i.e. the yield that would be obtained in a given locality under idealized conditions where the crop would be maintained free of any growth limitation other than solar radiation, temperature, and rainfall. In this study, CELSIUS is the result of empirical additions made to PYE in order to account for the following additional limiting factors: (i) reduction of rainfall infiltrating into the soil due to 
runoff using the model from Albergel et al. (1991), (ii) delayed crop emergence due to insufficient moisture in soils after sowing and crop destruction by extreme drought during the juvenile stage following the approach of Affholder (1997), and (iii) low nitrogen availability in soils. The latter factor is accounted for through a nitrogen-limiting coefficient (NLC) applied to leaf and biomass growth defined as:

$$
N L C=\operatorname{Min}\left[1 ; \alpha *\left(N_{\text {soil }}+N_{\text {inorg }}+N_{\text {org }}+N_{\text {symb }}\right) / I_{\text {fertmax }}\right]
$$

where $N_{\text {soil }}, N_{\text {inorg }}, N_{\text {org }}$, and $N_{\text {symb }}$ are the mineral nitrogen amounts available to crops from, respectively, soil organic matter mineralization, inorganic fertilization, mineralized $\mathrm{N}$ from organic fertilization, and symbiotic fixation of atmospheric $\mathrm{N}$ by leguminous crops, $I_{\text {fertmax }}$ is the level of nitrogen supply above which growth is not limited, and $\alpha$ a calibration coefficient (less than 1) accounting for losses of mineral $\mathrm{N}$ through volatilization and leaching.

CELSIUS also includes a management system component simulating the decision to sow the crop at the beginning of the season or after a drought-induced failure of the crop, following rules based on the sequence of rainfall within a pre-defined sowing period. This component was taken from Affholder (1997), in which it had been tested against actual sequences of sowing, emergence, failure and re-sowing observed in farmers' fields of the same region.

Parameters relative to the simulation of $Y w$ were set at values available in the literature when applicable and otherwise calibrated using the ESPACE-PRODCLIM and AMMA plot-level databases) following the method detailed in Affholder et al. (2013). The value of $\alpha / I_{\text {fertmax }}$, and in the case of groundnut, of $N_{\text {symb }}$, were calibrated by minimizing the cumulated quadratic error of simulated yields against observed yields of a sample of plots extracted from the database for which all $\mathrm{N}$ amounts brought by fertilization were available.

Appendix $[\mathrm{x}]$ provides a fully detailed mathematical description of CELSIUS as well as references to published models from which components where taken, when applicable, and details about model calibration and test against observed yields. The un-compiled software code is available on request to affholder@cirad.fr. 
Table 2 Description of the simulated cropping systems ${ }^{1}$

\begin{tabular}{llccccc}
\hline $\begin{array}{l}\text { Name of } \\
\text { cropping system }\end{array}$ & Crop & $\begin{array}{c}\text { Seed density } \\
\text { (nb of plants } / \mathrm{m}^{2} \text { ) }\end{array}$ & $\begin{array}{c}\text { Organic } \\
\text { nitrogen }\end{array}$ & $\begin{array}{c}\text { Inorganic } \\
\text { nitrogen }\end{array}$ & $\begin{array}{c}\text { Total N from } \\
\text { fertilization }\end{array}$ & $\begin{array}{c}\text { Type of cropping } \\
\text { system }\end{array}$ \\
\hline MilExt & Pearl millet & 1.2 & 0 & 0 & 0 & Extensive \\
MilManu & Pearl millet & 1.25 & 32 & 0 & 32 & Manure \\
MilFert & Pearl millet & 1.55 & 0 & 80 & 80 & Fertilizer \\
MilManuFert & Pearl millet & 1.65 & 40 & 80 & 120 & ManuFert \\
MaizeFert & Maize & 6 & 0 & 90 & 90 & Fertilizer \\
MaizeManuFert & Maize & 6 & 40 & 90 & 130 & ManuFert \\
GroundnutExt & Groundnut & 10 & 0 & 0 & 0 & Extensive \\
GroundnutManu & Groundnut & 10 & 14 & 0 & 14 & Manure \\
GroundnutFert & Groundnut & 12.5 & 0 & 7 & 7 & Fertilizer
\end{tabular}

${ }^{1}$ Currently practiced cropping systems are shown on a grey background, whereas more intensive alternatives are shown on 3 a white background.

\subsubsection{The economic model ANDERS}

Insurance demand takes place in the complex decision process of farmers, mobilizing diverse resources (natural, human, economic) to satisfy present and future family needs. Mathematical (linear or non-linear) programming models provide a convenient way to represent farmers' labor and cash allocation among a large range of agricultural, livestock and off-farm activities under several constraints. They allow considering simultaneously a wide range of technical parameters and economic nutritional or social constraints (e.g. Jacquet et al. 2011, Louichi et al., 2010; Paas et al., 2016, Sanfo and Gérard, 2012). Their multi-periodic modality is particularly suited to a highly risky environment with several strong constraints (Boussard and Daudin, 1988). Here we represent only one year because we focus on yearly crop insurance, with a premium paid at the beginning of the cropping season in exchange of an indemnity at harvest time if the rainfall-based index is below a predetermined threshold. This is consistent with the very short planning horizon generally observed when risks are high and people poor. In these conditions investment decisions, regarding equipment or livestock for example, based on expected returns on several years, cannot be represented dynamically and are set as exogenous parameters. By contrast it is possible to represent in details the intra-annual dynamics in which insurance takes place and the importance of strongly seasonal constraints. We divide the year into seven periods to reflect that labor, cash and stocks constraints are strongly seasonal. Inputs costs have to be paid at the beginning of the cropping season, while cash corresponding to harvest will be only available at the end of the period, consumption needs being smoothed all over the year (Table 3).

To account for risks, the objective function maximized in the model is the expected utility of income. Risk depends on yields and prices fluctuations represented using the concept of 


\begin{tabular}{|c|l|l|l|l|l|l|l|}
\hline Period & \multicolumn{1}{|c|}{$\begin{array}{c}\text { P1 } \\
15^{\text {th }} \text { May- } \\
20^{\text {th }} \text { June }\end{array}$} & $\begin{array}{c}\text { P2 } \\
21^{\text {st }} \text { June- } \\
15^{\text {th }} \text { July }\end{array}$ & $\begin{array}{c}\text { P3 } \\
16^{\text {th }} \text { July- } \\
30^{\text {th }} \text { August }\end{array}$ & $\begin{array}{c}\text { P4 } \\
31^{\text {th }} \text { August- } \\
25^{\text {th }} \text { Sept. }\end{array}$ & $\begin{array}{l}\text { P5 } \\
26^{\text {th }} \text { Sept.- } \\
30^{\text {th }} \text { Nov. }\end{array}$ & $\begin{array}{l}\text { P6 } \\
1^{\text {st }} \text { Dec.- } \\
14^{\text {th }} \text { May } \\
\text { (dry season) }\end{array}$ & $\begin{array}{l}\text { P7 } \\
\text { pext year } \\
\text { provisions }\end{array}$ \\
\hline $\begin{array}{c}\text { Main } \\
\text { agricultural } \\
\text { activities }\end{array}$ & $\begin{array}{l}\text { Soil } \\
\text { preparation. } \\
\text { Millet } \\
\text { sowing }\end{array}$ & $\begin{array}{l}\text { Soil } \\
\text { preparation. } \\
\text { Groundnut } \\
\text { and maize } \\
\text { sowing }\end{array}$ & $\begin{array}{l}\text { Manual } \\
\text { weeding }\end{array}$ & & $\begin{array}{l}\text { Millet, maize } \\
\text { and } \\
\text { groundnut } \\
\text { harvest }\end{array}$ & $\begin{array}{l}\text { Fattening } \\
\text { activities }\end{array}$ & $\begin{array}{l}\text { Sales of } \\
\text { fattened } \\
\text { animals }\end{array}$ \\
& & & & & \\
\end{tabular}

Where $E U$ is the expected income, $e$ the state of nature, $n$ the number of states of nature, $r_{a}$ the absolute risk aversion, $\pi_{e}$ the income, $w$ the initial wealth and $\operatorname{Exp}[$.$] is the exponential function.$

Expected utility increases with expected income and decreases with associated risk. A level of income is associated to each state of nature. (See Appendix F for equations list)

Income is calculated as the sum of the income generated by cropping, livestock and off-farm activities summed up with the assets variation at the end of the period, plus the insurance payoffs (if any) minus the insurance premium (if any) plus the various subsidies (if any).

Cropping activities are defined by a cropping system as presented in section 2.4 .1 , i.e. the combination of a given crop, cultivar and crop management, applied on a given field type. In ANDERS they are characterized by yield distributions of crop grain and above-ground biomass, as well as technical coefficients, specific to the field type, indicating the quantity of labor required, the draught animal requirements and the quantities of seed, manure and inorganic fertilizer.

A set of constraints is related to farm endowment in natural (land), human (labor) and economic resources (equipment, cash, access to credit). They state that utilizations of a resource cannot be greater than its availability for a given period of the year. They limit the access to land, credit, pasture and traction (with the possibility to rent animals). exponential one, implying a constant absolute risk aversion (CARA).

$$
E U=\frac{1}{n} \sum_{e=1}^{n} 1-\operatorname{Exp}\left[-r_{a}\left(\pi_{e}+w\right)\right]
$$


In each period, the labor need for agricultural activity or livestock can be filled through family labor or hired worker. Family members can work on the farm or outside.

The cash equations (F7-F8 in Appendix F) focus on the money flows for each period and ensures that it remains positive. Money comes in at the harvest time or when selling animals, while expenditures are related either to cropping or animals activities or to household's consumption. A limited credit is available.

The supply-utilization account splits the harvest in several utilizations: selling, storage, human or animal consumption. It is combined with a nutritional constraint which ensures that the household consumed enough kcal in each period to represent the food security objective.

Energy and protein balances are also included for animals (digested nitrogen and dry matter). They can be fed through pasture, grain, straw and purchased feedstuff. Beside their nutritional needs, they are characterized by technical coefficients indicating labor required for tending and herding, vaccines and other veterinary costs. A stochastic return by head is assumed to take risk into account. By contrast the model includes the decision of buying animals for fattening in the sixth period.

The interactions between the cropping and livestock systems are considered through draught animal power, feeding of animals with suitable crop products and production of farm manure.

Final constraints oblige to keep at the end of simulation the same amount of cash and kcal in stocks in average over the states of nature as at the beginning, so that a new year could start in adequate conditions. However, to account for the social links between farmers at the village level providing informal insurance, the amount of cash and kcal in stocks in each state of nature has only to reach half of its initial value.

Finally exogenous parameters include technical input-output coefficients and the farm endowment in resources (natural, human, economic) while endogenous variables represents the decisions on (i) land allocation among cropping systems, (ii) insurance demand, (iii) labor and cash allocation among activities (crop production, livestock, off-farm).

The key output variables to be analyzed are the level of production, the cropping systems chosen, the level of animal fattening activity, the average income, the coefficient of variation of income, and the certain equivalent income (CEI) i.e. the certain income which provides the same utility as a given probability distribution of uncertain incomes (equation F1B in Appendix F). 
Appendix $D$ presents the model calibration and its evaluation against observations and appendix $E$ the gross margin distribution for each cropping system. Figure D1 shows the good consistency between the observed production choices and the simulations in the baseline scenario, i.e. a simulation under the current environment of farms (without considering any hypothetical policy).

\subsection{Implementation of insurance in the model}

\subsubsection{Weather index-based insurance (WII)}

As rainfall distribution is the main climatic factor affecting yields in the study area, we developed and used a composite rainfall-based index, for millet, maize and groundnut. This index is very similar to the ones used in the insurance projects which are currently implemented in West Africa1 and other regions of the world, as it splits the crop growing cycle into three stages to account for variations in drought sensitivity throughout the crop cycle2: (i) juvenile and earlier vegetative phases, (ii) later vegetative phases and flowering and (iii) grain development (fructification). For each stage, a rainfall-based index is used to determine an indemnity to be paid (if any) according to (i) the rainfall amount recorded during the given phase, (ii) the insured value, (iii) the phase-specific trigger value (amount of rainfall below which indemnity starts) and (iv) the phase-specific exit value (amount of rainfall below which the total indemnity is paid). Between the trigger and the exit values, the indemnity is proportional to rainfall. Rainfall amounts are capped at $80 \mathrm{~mm}$ per dekad (10-day period) to account for runoff and drainage. The global indemnity to be paid is the sum of the three indemnities identified above and its value is capped at the maximal insured value, 100000 FCFA (152 $€$ ) which is the highest possible expenditure on external inputs (Fig. 4). Under each phase, the insured value is also 100000 FCFA.

${ }^{1}$ Insurance pilot projects initiated by World Bank and PlaNet Guarantee in West African countries (Senegal, Burkina Faso, Mali and Benin).

${ }^{2}$ We also tested pure rainfall indices but the results showed a much lower CEI gain compared to the three-phase index retained. 


\begin{tabular}{|c|c|c|c|c|c|c|}
\hline \multirow{2}{*}{$\begin{array}{l}\text { Crop } \\
\text { Protection level }^{1}\end{array}$} & \multicolumn{2}{|c|}{ Millet } & \multicolumn{2}{|c|}{ Maize } & \multicolumn{2}{|c|}{ Groundnut } \\
\hline & Lowest & Highest & Lowest & Highest & Lowest & Highest \\
\hline Premium & 4387 & 21807 & 5200 & 22928 & 2827 & 23448 \\
\hline Indemnity frequency ${ }^{2}$ & $10 \%$ & $30 \%$ & $15 \%$ & $30 \%$ & $5 \%$ & $30 \%$ \\
\hline Average indemnity & 3375 & 16775 & 4000 & 17637 & 2175 & 18037 \\
\hline Minimum Indemnity & 31500 & 30000 & 19000 & 14750 & 43500 & 3500 \\
\hline Maximum Indemnity & 36000 & 100000 & 34750 & 100000 & 43500 & 63000 \\
\hline
\end{tabular}

For each year of simulation the start of the index was forced to the sowing date of the crop as simulated by CELSIUS. For a given crop variety we developed and used several indices having the same structure (crop phases, rainfall capping value) but different trigger, exit, and level of coverage in order to introduce a menu of insurance options, with different levels of protection and associated premium cost available to the simulated farmers.

${ }^{1}$ the level of protection depends on the coverage level, the trigger and the exit values. According to the crop, 9 to 12 contracts are available per crop. In the table, we only show the least and the most two protecting contracts for each crop.

${ }^{2}$ Indemnity frequency is a ratio: the number of times the farmer receives an indemnity over the number of states of nature. and field type as follows:

$$
\left.\mathrm{I}_{\mathrm{e}, \mathrm{ac}, \mathrm{z}}^{\mathrm{WII}}=\operatorname{Min}\left\{\rho \mathrm{M}, \operatorname{Max}\left[0, \sum_{\text {stage }} \text { indemnity(stage }\right)\right]\right\}
$$

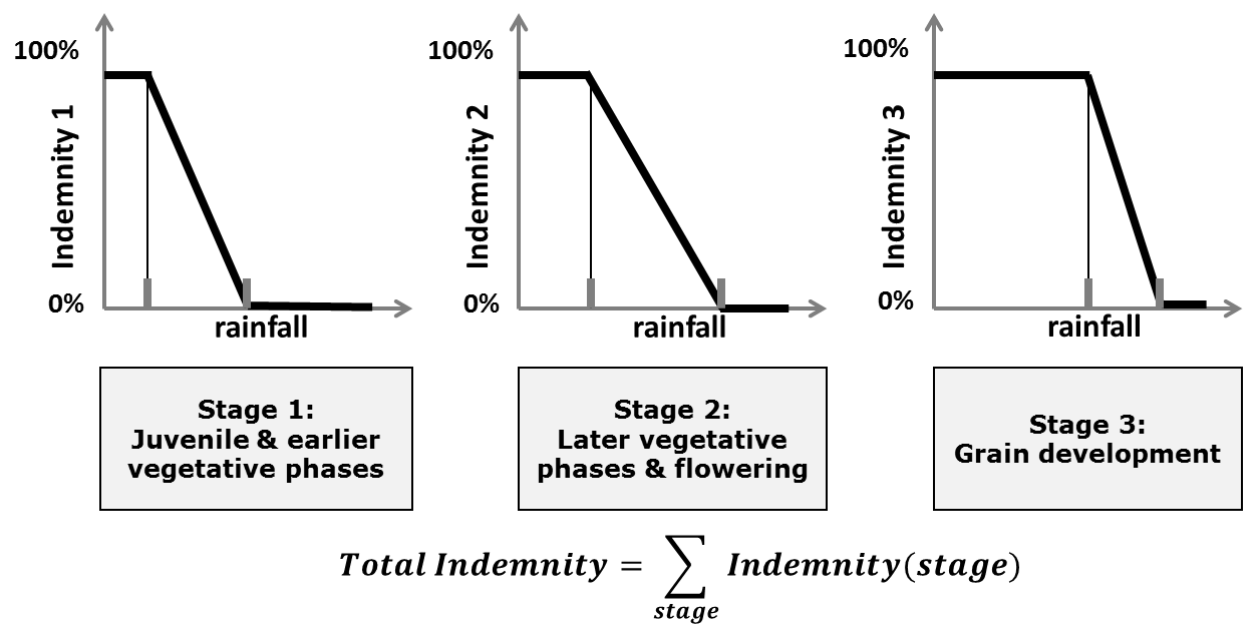

Figure 4: Mechanism of the composite rainfall index-based insurance

Global indemnities for this weather index-based insurance (WII) are calculated for each crop 
Where $\mathrm{I}_{\mathrm{e}, \mathrm{ac}, \mathrm{z}}^{\mathrm{WII}}$ is the indemnity at state e for the cropping activity ac and the field type $\mathrm{z}$. M is

2 the maximal insured value (in FCFA/ha), $\rho$ is the coverage level, and indemnity(stage) is the indemnity under a given phase.

Depending on the chosen option, the frequency of indemnity payments to simulated farmers varies between $5 \%$ and $40 \%$ of the years being considered in the weather data series used in the study. The premium is equal to the expected indemnity payment plus a loading factor accounting for administrative costs and insurer's profit. This parameter is fixed at $30 \%$ in accordance with previous literature (Berg et al., 2009). Details on the WII are given in table 4.

\subsubsection{Crop yield insurance (CYI)}

Furthermore, in order to assess the effect of the basis risk (the imperfect correlation between the index and the actual farmer's crop yield) on the farmer's decision to insure or not, we also computed an index perfectly correlated with yields, the farmer's yield itself. Indemnities for this crop yield insurance (CYI) are calculated for each crop and field type using the following indemnity function:

$$
\mathrm{I}_{\mathrm{e}, \mathrm{ac}, \mathrm{z}}^{\mathrm{CYI}}=\operatorname{Min}\left\{\mathrm{M}, \operatorname{Max}\left[0,\left(\rho \bar{y}-\mathrm{y}_{\mathrm{e}}\right) \mathrm{P}\right]\right\}
$$

Where $\mathrm{I}_{\mathrm{e}, \mathrm{ac}, \mathrm{z}}^{\mathrm{CYI}}$ is the indemnity at state e for the cropping activity ac and the field type $\mathrm{z} . \mathrm{M}$ is the maximal insured value (in FCFA/ha), $\mathrm{P}$ is the value of damages estimated the average crop price (in FCFA $/ \mathrm{kg}$ ) and $\rho$ is the yield coverage specified as a percentage of the farmer's average yield $\bar{y}$ over the 20 states of nature (in $\mathrm{kg} / \mathrm{ha}$ ). We fixed M at $100000 \mathrm{FCFA} / \mathrm{ha}$ which is the highest possible expenditure on external inputs and corresponds to the same insured value as the weather index. Several values of $\rho$ were chosen $(80 \%, 90 \%$ and $100 \%)$ in order to obtain a menu of insurance options available to the farmer in this case too. The loading factor was also fixed at $30 \%$. This $\mathrm{CYI}$ is purely hypothetical but provides a useful benchmark, the limit towards which index-based insurance would tend, should the index become perfect, i.e. the nil basis risk situation. Details on the CYI are given in table 5. 
Table 5. Description of the crop yield insurances (CYI) in the Sine zone

\begin{tabular}{lllllll}
\hline Crop & & Millet & & Maize & \multicolumn{2}{c}{ Groundnut } \\
\hline Protection level & Lowest & Highest & Lowest & Highest & Lowest & Highest \\
Premium & 3303 & 27536 & 5046 & 16727 & 2274 & 12902 \\
Indemnity frequency & $10 \%$ & $35 \%$ & $20 \%$ & $40 \%$ & $5 \%$ & $35 \%$ \\
Average indemnity & 2541 & 21181 & 3882 & 12867 & 1749 & 9924 \\
Minimum Indemnity & 1490 & 85 & 300 & 1252 & 34985 & 6877 \\
Maximum Indemnity & 49329 & 100000 & 31290 & 60752 & 34985 & 77845 \\
\hline
\end{tabular}

\section{Scenarios and results}

\subsection{Simulated scenarios}

We first introduce three scenarios without subsidies:

- Baseline, in which no insurance is available.

- WII, in which a weather index-based insurance, as described in section 2.5 , is available.

- CYl, hypothetical crop-yield insurance with no basis risk, as described in section 2.5. The comparison between $\mathrm{CYI}$ and WII quantifies the impact of the basis risk.

We then introduce four scenarios in which the same amount of public funds is spent. We considered policies typically debated among stakeholders of Sudano-Sahelian West Africa, using scenarios into which, as compared to the WII scenario, the following changes are introduced:

- Premium subsidy scenario (PremiumSub): the WII premium cost is reduced

- Loan program scenario (CreditSub): a combination of decreasing the interest rate and increasing the maximum access to credit.

- A fertilizer subsidy scenario (FertSub): the cost of fertilizers is reduced.

- A cash transfer program (CashTrsf): simulated farmers unconditionally receive a sum of money.

In these scenarios, unsubsidized WII is not available, and the constant amount of public funds used is set with reference to the first scenario, where the subsidy covers $60 \%$ of the cost of the insurance premium paid by simulated farmers, consistent with the fact that most agricultural insurance around the world is heavily subsidized (Mahul 2012). We first ran the premium subsidy scenario (PremiumSub). This allowed determining the government expenditure level under this scenario on the basis of the level of adoption of subsidized WII by simulated farmers. The amount so calculated was then used as the public expenditure level when running the other three scenarios (i.e. 
1 the total amount of government expenditure in each scenario is equal to the expenditure

2 corresponding to the PremiumSub scenario). In the case of the CreditSub scenario the interest rate is

3 decreased by $75 \%$ compared to the baseline scenario (from $14 \%$ to $3.5 \%$ ), and if this is not sufficient

4 to make the cost of the program match the public budget, the upper limit of credit accessibility is

5 increased. Furthermore, in every case we assumed that the subsidy does not provoke an increase in

6 the suppliers' prices (i.e. the insurance premium, the interest rate and the price of fertilizers

7 respectively). Similarly, the possible output price decrease due to an increase in supply is not considered. Estimating how these prices might change is beyond the scope of the present paper and would require the increase in suppliers' profits to be quantified in order to provide a consistent costbenefit analysis. Yet the reader should keep in mind that by neglecting these changes, we possibly overestimate the gains from these scenarios, compared to the scenarios without subsidies.

Finally, in order to study the effect of combining access to WII with subsidized credit, fertilizer or cash transfers, we considered 3 additional scenarios, CreditSub-I, FertSub-I and CashTrsf-I, as variants of the scenarios CreditSub, FertSub and CashTrsf respectively, in which the unsubsidized WII insurance is available in combination with the subsidy program. Table 6 summarizes the simulations performed:

Table 6 Description of the programs simulated

\begin{tabular}{|c|c|c|c|c|c|c|c|c|c|c|}
\hline Scenario $\rightarrow$ & Baseline & WII & $\mathrm{CYI}$ & PremiumSub & CreditSub & CreditSub-I & FertSub & FertSub-I & CashTrsf & CashTrsf-I \\
\hline WII available? & No & Yes & No & Yes & No & Yes & No & Yes & No & Yes \\
\hline CYI available? & No & No & Yes & No & No & No & No & No & No & No \\
\hline Insurance subsidy? & No & No & No & $60 \%$ of premium & No & No & No & No & No & No \\
\hline Credit subsidized? & No & No & No & No & \multicolumn{2}{|c|}{$\begin{array}{c}\text { interest rate at } 3.5 \% \\
\text { instead of } 14 \% \text { plus } \\
\text { enhanced credit access }\end{array}$} & No & No & No & No \\
\hline $\begin{array}{l}\text { Fertilizers } \\
\text { subsidized? }\end{array}$ & No & No & No & No & No & No & \multicolumn{2}{|c|}{$\begin{array}{l}\text { reduced fertilizer } \\
\text { price }\end{array}$} & No & No \\
\hline Cash transfer? & No & No & No & No & No & No & No & No & Cash trans & fer program \\
\hline
\end{tabular}

19

\subsection{Insurance gains and basis risk}

When (unsubsidized) WII or CYI is introduced into the model as a possible option, only the Sine1 and Sine2 farms adopt it, with a notable impact on CEI and farm plans. Saloum1 and Saloum2 adopt neither WII nor CYI in the simulations (Table 7). 
Sine1, the most constrained farm-type in the Sine subzone, benefits the most from WII with a 18\% increase in CEI (from 115020 FCFA i.e. 175€/worker in the baseline scenario to 135561 FCFA i.e. 142€/worker) and a 1\% increase in expected income (from 146604 FCFA i.e. 223€/worker to 148264 FCFA i.e. $226 €$ /worker. This large increase in the CEI is consistent with the high level of risk aversion and vulnerability to damaging events of this farm-type. Given its small size and its strong cash and credit constraints, yield risk has a large impact on its income that can be reduced by insurance. A total of 54467 FCFA (84 $€$ ) is paid in insurance premiums for the whole farm. 42968 FCFA (65 €) are paid for millet for which $67 \%$ of total output is insured. The average indemnity paid is 110174 FCFA $(168 €)$ in $30 \%$ of the states of nature. $100 \%$ of the groundnut is also insured for a total premium of 11499 FCFA (17 €). The average payment is 29484 FCFA (45€) in 30\% of the states of nature. As only $70 \%$ in average are given back to simulated farmers in the form of indemnities and the rest is the loading factor, the welfare gain for the farmer arises through the drop of the income variability (the coefficient of income variation drops by -9 percentage points) rather than through the improvement in expected income. As expected, CYI leads to higher welfare and income gains $(+22 \%$ in CEI and $+4 \%$ in expected income), relatively to WII. These higher benefits of CYI are due to the absence of basis risk which makes the insurance more efficient for a given amount of premium. Hence, for the same drop of income variability (-9 percentage points), the amount of insurance premium to pay is only 34518 FCFA (52€), only for millet production (100\% of the production is covered). Changes in the farming system induced by the supply of insurance are significant. A large portion of the land dedicated to groundnut is converted to millet (+34 percentage points and +45 percentage points under WII and CYI, respectively). The observed switch from groundnut to millet is explained by the price volatility that becomes the main source of risk when crop insurance is provided. Given that price volatility is higher for groundnut than for cereals, the simulated farmer allocates more land to millet. Moreover, insurance reduces the yield risk which entails intensification of millet. Given the level of land and liquidity constraints, the intensification of millet is necessarily at the expense of another crop, here groundnut which requires cash, even under the extensive cropping system.

WII has less impact on Sine 2 than on Sine1. CEI increases by only $2 \%$ and $4 \%$ under WII and CYI, respectively, while expected income decreases by $-5 \%$ and $-4.5 \%$ respectively, showing that the loading factor is not totally compensated by production changes. Insurance premium amounts to 73195 FCFA (111€) and 47079 FCFA (71€) under WII and CYI, respectively. Insurance is only used for millet, and cover $43 \%$ and $53 \%$ of total production of this crop, respectively. Here also, given that the drops in the coefficient of income variation are equal between both insurances (-6 percentage points), the lower premium for the CYI is attributable to the absence of basis risk that makes the insurance more efficient for a given amount of premium. As observed for Sine1, although to a lower 
extent, there is an increase in the area allocated to millet at the expense of groundnut. Under WII, technical changes are very limited, while they are significant under CYI under which fertilizer-based cropping systems replace extensive ones. Finally, while cow fattening increases under both types of insurances, sheep fattening increases under CYI only.

In the Saloum subzone, there is no take-up of insurance which can be explained by the lower climate variability so that cropping systems are characterized by lower exposure to yield risk. These results highlight the fact that the attractiveness of unsubsidized insurance depends on the biophysical and socioeconomic environments (as shown by the different responses to the introduction of insurance between the two subzones) but also on the farm characteristics (as shown by the different responses to the introduction of insurance between the two farm-types of Sine).

Table 7 Impacts of the introduction of unsubsidized weather (WII) and crop-yield (CYI) insurances relative to the baseline (BL) scenario on the main model's outputs

\begin{tabular}{|c|c|c|c|c|c|c|c|c|c|c|}
\hline & \multicolumn{3}{|c|}{ Sine1 } & \multicolumn{3}{|c|}{ Sine2 } & \multicolumn{2}{|c|}{ Saloum1 } & \multicolumn{2}{|c|}{ Saloum2 } \\
\hline & $B L$ & WII & CYI & $\mathrm{BL}$ & WII & $\mathrm{CYI}$ & $B L$ & WII/CYI & $B L$ & WII/CYI \\
\hline CEI/worker & 115020 & $18^{(\%)}$ & 22 & 232152 & 2 & 4 & 150183 & 0 & 205577 & 0 \\
\hline Mean income/worker & 146604 & $1^{(\%)}$ & 4 & 272920 & -5 & -4.5 & 167067 & 0 & 225407 & 0 \\
\hline CV income & $23 \%$ & $-9^{(p p)}$ & -9 & $22.3 \%$ & -6 & -6 & $15.8 \%$ & 0 & $19.1 \%$ & 0 \\
\hline Total Premium & $\mathrm{n} / \mathrm{a}$ & 54467 & 34518 & $\mathrm{n} / \mathrm{a}$ & 73195 & 47079 & $n / a$ & 0 & $\mathrm{n} / \mathrm{a}$ & 0 \\
\hline Millet prod./worker & $362 \mathrm{~kg}$ & $+34^{(\mathrm{pp})}$ & 0.45 & $777 \mathrm{~kg}$ & +23 & 0.32 & $467 \mathrm{~kg}$ & 0 & $678 \mathrm{~kg}$ & 0 \\
\hline Maize prod./worker & $26 \mathrm{~kg}$ & $-2^{(\mathrm{pp})}$ & -0.02 & $0 \mathrm{~kg}$ & 0 & 0 & 136 kg & 0 & 363 kg & 0 \\
\hline Groundnut prod./worker & $185 \mathrm{~kg}$ & $-32^{(\mathrm{pp})}$ & -0.43 & $349 \mathrm{~kg}$ & -23 & -0.32 & $244 \mathrm{~kg}$ & 0 & 356 kg & 0 \\
\hline Extensive & 2.33 ha & $-27^{(\mathrm{pp})}$ & -0.49 & 6.24 ha & -2 & -0.11 & 4.28 ha & 0 & 9.36 & 0 \\
\hline Manure & 1.11 ha & $+2^{(\mathrm{pp})}$ & 0.11 & 3.68 ha & -2 & -0.02 & 1.83 ha & 0 & 3.01 & 0 \\
\hline Fertilizer & 0 ha & $+27^{(\mathrm{pp})}$ & 0.4 & 0.59 ha & +5 & 0.13 & 0.04 ha & 0 & 2.27 & 0 \\
\hline ManuFert & 0.06 ha & $-2^{(p p)}$ & -0.02 & 0 ha & 0 & 0 & 0.34 ha & 0 & 0.55 & 0 \\
\hline Cow fattening & 0.4 head & $0.22^{(\mathrm{a})}$ & 0.22 & 1.6 head & 0.61 & 0.49 & $\mathrm{n} / \mathrm{a}$ & $\mathrm{n} / \mathrm{a}$ & $\mathrm{n} / \mathrm{a}$ & $\mathrm{n} / \mathrm{a}$ \\
\hline Sheep fattening & 0 head & $0^{(\mathrm{a})}$ & 2.28 & 4.8 head & -4.81 & 0.25 & 0 head & 0 & 0.8 head & 0 \\
\hline
\end{tabular}

Note: Under each farm-type, BL column shows the output's values corresponding to the baseline scenario (CEI and income are given in FCFA). WII and CYI columns show the changes relative to the baseline with weather-index- and crop yield insurances, respectively. Extensive, Manure, Fertilizer and ManuFert refer to the type of cropping systems given in Table 2. Changes are displayed in the following units: \% represents the percentage change relative to the baseline scenario; $p p$ indicates changes in percentage points relative to the baseline scenario (e.g. Extensive gives the difference in percentage points of the proportion of the total area dedicated to this given cropping system, and (a) means changes in absolute value (head of livestock). Total premiums are given in FCFA spent (no percentage change can be calculated since there is no insurance in the baseline scenario).

\subsection{Subsidy program scenarios}

As explained above, subsidy program scenarios have been simulated at a constant level of public spending which is determined, for each farm-type, from the insurance premium subsidy 
scenario (60\% of the insurance premium). Since the amount of spending in the premium subsidy scenario depends on the farm-type (Table 8), this hampers comparisons between farm-types.

\subsubsection{Impact of subsidy programs on simulated farmers' CEI and expected income}

Table 8 gives the impact of the subsidy programs on the farmer's CEI and expected income and also ranks these programs in term of CEl. PremiumSub is never the best use of public funds; it is even the worst one for every farm-type in term of expected income, and the worst for three farm-types out of four in term of CEI. The only farm-type in which PremiumSub does not bring the lowest CEI is Sine1, but even there it is only ranked $4^{\text {th }}$ out of 7 scenarios and is dominated by all the scenarios in which unsubsidized insurance is available: CreditSub-I, FertSub-I and CashTrsf-I. Hence subsidizing insurance is always the worst use of public funds, compared to scenarios in which insurance is available but not subsidized. CreditSub-I is always the best use of public funds in term of CEI, even though in Sine1 CashTrsf-I and FertSub-I bring the same outcome. These results indicate that for a given level of public spending, the simulated farmers' situation can improve more by alleviating the cash constraint (which prevents farmers from buying productive inputs) than by mitigating the impact of a bad weather.

Another insight from Tables 8 and 9 is that in Sine2, while introducing unsubsidized WII increases CEI by only $2 \%$ in a scenario without any subsidy (Table 7), it raises CEI by almost 8 percentage points if credit is subsidized (from 9.7 to $17.6 \%$, cf. Table 8 ). This indicates that the value of mitigating the impact of a bad weather is higher when the cash constraint is alleviated. This complementarity between insurance and credit is consistent with the results of the contingent valuation study lead in Ethiopia by McIntosh et al. (2013) which indicates a higher willingness to purchase insurance when interlinked with a credit on inputs.

Comparing our two subzones, we see that in Sine insurance is taken under every scenario in which it is available, while in Saloum it is taken only under PremiumSub and, for Saloum2, under CreditSub-I. As explained above, this is due to the lower risk of drought in Saloum. 
2 Table 8. Impact of the subsidy programs on farmer's CEI and expected income (\% increase relative to the baseline scenario) and their ranking

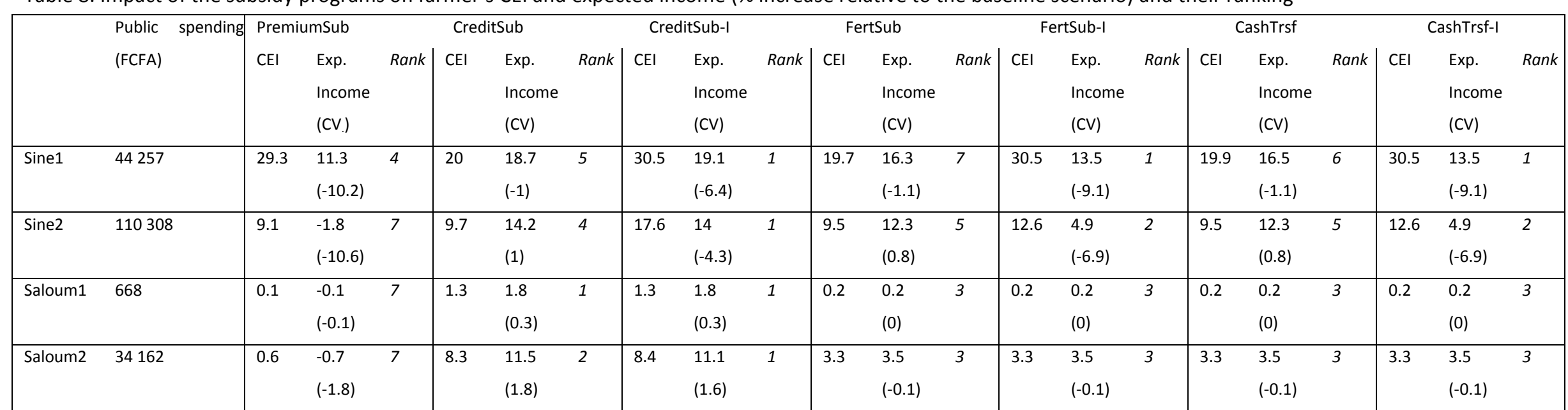

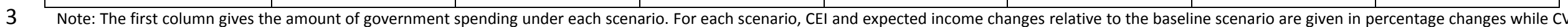
of income change is given in percentage point. The Rank column gives the ranking of the policy based on the percentage change in CEI. 
Table 9. Impact of the subsidy programs on crop production and animal fattening (\% increase relative to the baseline scenario)

\begin{tabular}{|c|c|c|c|c|c|c|c|c|}
\hline & & PremiumSub & CreditSub & CreditSub-I & FertSub & FertSub-I & CashTrsf & CashTrsf-I \\
\hline \multirow{5}{*}{ Sine 1} & Cereal $^{1}$ & 101.9 & 45.9 & 126.3 & 19.2 & 100 & 11.1 & 100 \\
\hline & Groundnut & -74.7 & -6.9 & -62.2 & 14.7 & -65 & 19.4 & -65 \\
\hline & Grain production value & 16.8 & 20.8 & 35.6 & 17.7 & 20.6 & 15.5 & 20.6 \\
\hline & Cow fat. ${ }^{2}$ & 0.4 & 1 & 0.9 & 0.1 & 0.3 & 0.1 & 0.3 \\
\hline & Sheep fat. & 0.2 & 4.8 & 9.5 & 0 & 1.2 & 0 & 1.2 \\
\hline \multirow{5}{*}{ Sine2 } & Cereal & 55.2 & 40.4 & 117.4 & 10.2 & 50.7 & 10.2 & 50.7 \\
\hline & Groundnut & -77.8 & -7.3 & -64 & 14.9 & -53.2 & 14.9 & -53.3 \\
\hline & Grain production value & -7.3 & 18 & 32 & 12.4 & 1.9 & 12.4 & 1.9 \\
\hline & Cow fat. & 0.8 & 2 & 2.1 & 0.1 & 1.1 & 0.1 & 1.1 \\
\hline & Sheep fat. & -4.2 & 13.4 & 20.3 & 2.3 & -4.8 & 2.3 & -4.8 \\
\hline \multirow{4}{*}{ Saloum1 } & Cereal & 1.2 & 4.1 & 4.1 & 0.2 & 0.2 & 0.2 & 0.2 \\
\hline & Groundnut & -1.9 & 3.9 & 3.9 & 0.2 & 0.2 & 0.2 & 0.2 \\
\hline & Grain production value & -0.1 & 3.9 & 3.9 & 0.2 & 0.2 & 0.2 & 0.2 \\
\hline & Sheep fat. & 0 & 0 & 0 & 0 & 0 & 0 & 0 \\
\hline \multirow{4}{*}{ Saloum2 } & Cereal & 27.7 & 16.4 & 18.8 & 2.3 & 2.3 & 2.3 & 2.3 \\
\hline & Groundnut & -45.7 & 20 & 16.5 & 4 & 4 & 4 & 4 \\
\hline & Grain production value & 0.2 & 20 & 19.8 & 2.8 & 2.8 & 2.8 & 2.8 \\
\hline & Sheep fat. & 5 & -0.9 & -0.9 & -0.2 & -0.2 & -0.2 & -0.2 \\
\hline
\end{tabular}

$2 \quad{ }^{1}$ Grain production and value changes are given as percentages relative to the baseline scenario; ${ }^{2}$ Cow fattening and sheep fattening changes are given in absolute value relative to the baseline scenario. 


\subsubsection{Impact of the subsidy programs on the development of intensive cereal crops or of fattening}

activity

As a simple way to assess the impact of our scenarios in terms of crop intensification, we compared the total value of grain production (cereal and groundnut), thus aggregating crops with different prices.

The only farm-type in which PremiumSub entails intensification is Sine1 where the total value of grain production increases by $16.8 \%$ (Table 9), due to a surge in the use of fertilizers (Fig. 5). The explanation goes as follows: in case a very bad weather, fertilizers reduce income (Figure E.1) because they do not increase yield significantly while the farmer must purchase them. Because of risk aversion, intensification reduces farmers' CEI, so they are not adopted even though they would raise average income. Under PremiumSub, fertilizers increase average income without worsening the situation under very bad weather since in this case farmers receive an indemnity. Nevertheless, even for Sine1, the increase in grain value is lower than under other policies. For the other farm-types, while subsidizing WII increases simulated farmers' CEI, it neither directly provides the cash required for increasing the herds producing manure nor for purchasing inorganic fertilizer. On the contrary, since the insurance premium must be paid upfront it reduces the cash available to invest in external inputs.

In Sine, animal fattening activity increases a lot under CreditSub and CreditSub-I, which provide the relatively large investments required for such activities. Hence, these scenarios foster the greatest amount of cereal intensification since the use of both manure (through the fattening activity) and inorganic fertilizer (through purchase) greatly increases (Fig. 5). Furthermore, the availability of (unsubsidized) insurance reinforces the positive effect of credit or fertilizer subsidies as well as of cash transfer on cereal intensification, the latter development being highest under CreditSub-I. Two factors explain this intensification of millet: (i) insurance is more efficient at stabilizing the gross margin of millet than that of groundnut, due to the strong component of price instability in gross margin variation for groundnut, which cannot be reduced with the use of a WII; (ii) the labor requirement for millet is far lower (around 40\%) than for groundnut. WII allows simulated farmers to mitigate crop risk and thus to accept more risk in fattening activities, which are the most profitable but require labor (and cash obtained thanks to the policy tools). This is why the availability of WII in addition to a subsidy program encourages the intensive production of millet and decreases the groundnut area which releases labor used for fattening activities. When WII is unavailable, the tested scenarios lead to a limited increase in both cereal and groundnut productions and to a slightly enhanced animal fattening activity (Table 9). 
In the Saloum subzone, the simulated programs increase the production of both cereals and groundnut, through an increased use of inorganic fertilizer (in Saloum1 yet, the increase is barely perceptible because of the very low amount of subsidy). The subsidy programs lead to a reduction in the area allocated to extensively managed millet and an increase in fertilized millet and fertilized maize, the latter two being more profitable but also more risky. Furthermore, as in the Sine subzone, the loan program produces the largest development of intensive cereals.

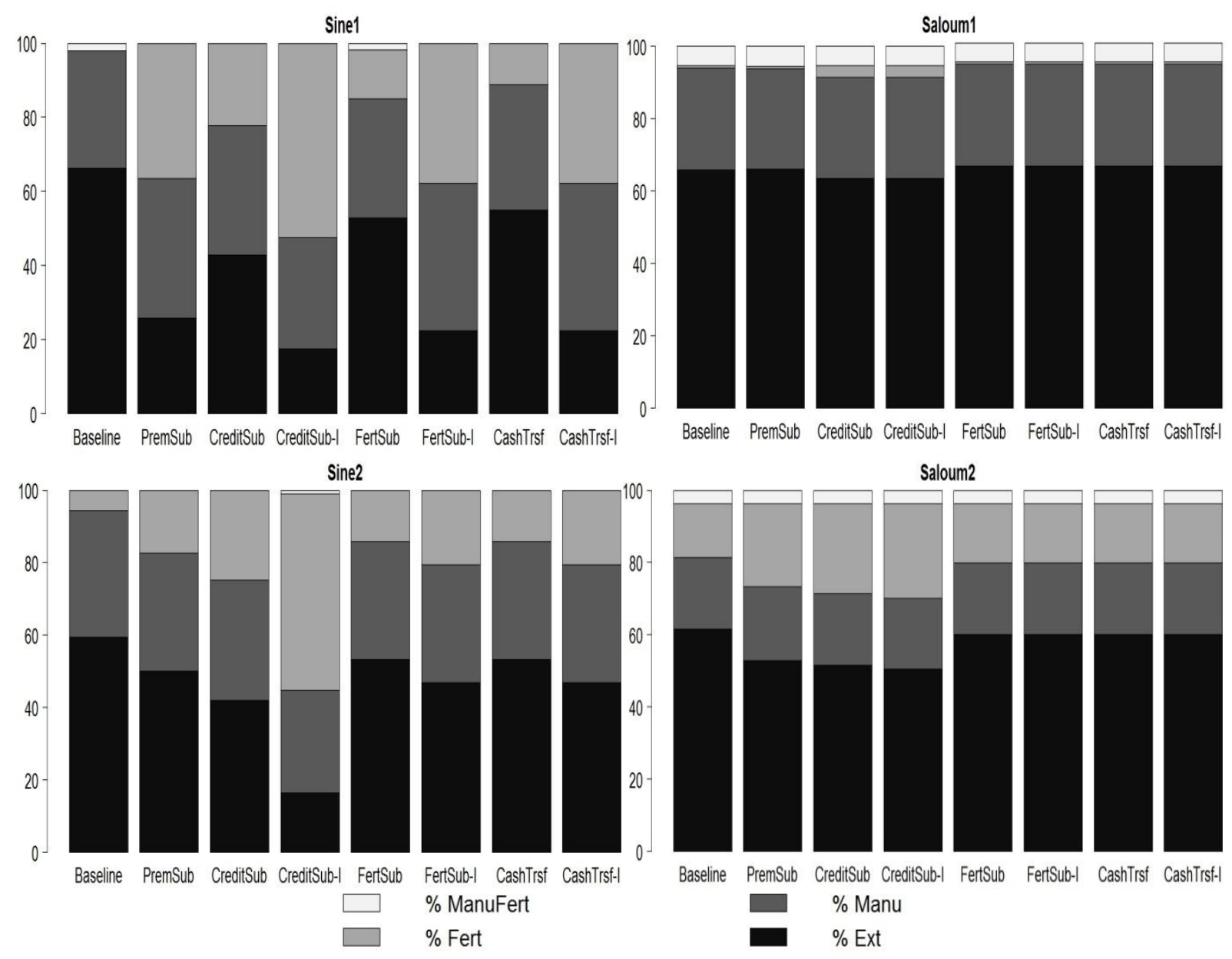

Figure 5: Share of land across cropping systems under each scenario for Sine (left) and Saloum (right).

\section{Discussion and conclusion}

Although in the mind of numerous stakeholders the groundnut basin of Senegal may be a region of the typical minimum size for agricultural policy design, the relative impacts at farm level of the policies tested strongly differ between the two subzones that we considered. These subzones show differences in rainfall distributions that influence only slightly the current production systems, remarkably similar in the two subzones. In contrast, our study suggests that these differences in 
rainfall have strong consequences in terms of the potential benefit of weather index insurance. In the wetter subzone (Saloum), the benefit from insurance is very low because the risk of water stress on crops is not the major constraint faced by simulated farmers even using more intensive cropping systems. Subsidizing the insurance premium by $60 \%$ (PremiumSub) induces simulated farmers to take up insurance but is much less efficient at increasing their expected utility or production than other uses of public funds, i.e. subsidizing credit (CreditSub) and fertilizers (FertSub), or just transferring cash as a lump sum (CashTrsf).

In the drier subzone (Sine), insurance, even unsubsidized (Insu), increases simulated farmers' utility, especially for the poorest ones. Simulated farmers respond to insurance by increasing their cow fattening activity, which allows them to increase millet yield by spreading more manure on the fields. For the less cash-constrained farms, crop intensification is further developed by using inorganic fertilizers on millet. However, here again, subsidizing insurance is not the best possible use of public funds, because the cash availability constraint clearly prevails over other constraints in the way simulated farmers can develop short-term fattening activities or intensive cereal production, which are the two main pathways for increasing farm income considered in this study.

The direct policy implication of these results is that while a public intervention to develop weather index insurance in the driest part of the Sudano-Sahelian zone may be justified, permanently subsidizing insurance, a current practice worldwide, is not. In areas prone to yield risk, the most benefit was seen from bundling government subsidies on other climate risk variables (e.g. subsidized loans, fertilizers or cash transfers) with unsubsidised insurance. This echoes the experience of operational programmes that have scaled up such as the R4 Resilience programme implemented recently in Senegal (Greatrex et al., 2015) or ACRE, where (unsubsidized) insurance is integrated with government interventions.

Four limits to our work, all of which reinforce the latter conclusion, are worth pointing out. First, when analyzing subsidies, we have deliberately excluded their possible inflationary impact on the subsidized goods and services (loans, fertilizers and insurance contracts). Hence, we may overestimate the benefits of these subsidies to farmers.

Second, as we ignored yield variations due to factors other than rainfall and fertility, the insurance index retained is necessarily better correlated to simulated yields than to the actual ones, which include idiosyncratic shocks (Leblois et al., 2013). Among these shocks are insect attacks or health problems which can reduce the workforce available at critical times. As a result, we underestimate the basis risk and overestimate the benefits of weather-index insurance. 
Third, it would be worth analyzing more policy and technical options. For example, we did not assess dry-resistant seeds bundled with credit and insurance that may be relevant to this area. We also did not test different business models of index insurance programmes (e.g. replanting guarantee, meso-insurance) that are promising ways to implement index insurances. There are also more crop management options, especially (i) those based on the principles of ecological intensification such as the retention of crop residues on the soil, expected to reduce water runoff and soil evaporation and to increase soil fertility (at the expense, however, of the loss of the corresponding amount of residues as feed contributing to livestock and manure production), and (ii) those pertaining to "climate-smart" agriculture such as the decision whether or not to use fertilizers, depending on accumulated rainfall and seasonal or short-term weather predictions (Roudier et al., 2016). It would also be worth assessing the efficiency of subsidies to other inputs than fertilizers (e.g. seeds of improved cultivars with drought resistance characteristics). Such enhanced analyses would require further investigations at field scale. Since these options typically mitigate the weather risk, they would most likely reduce the demand for weather-index insurance.

Fourth, in reality, WII face many obstacles which were not represented in the model, in particular widespread lack of trust in insurance products in general, and of knowledge of this kind of insurance products.

Since all these limits lead to overestimate the benefit from insurance, overcoming them could only reinforce our conclusion that while there may be a room for WII, there is little rationale for subsidizing them permanently, at least at the farm level in the kind of environment of our study. Our result on the superiority of subsidizing credit rather than insurance matches the view expressed by farmers themselves in surveys in similar regions (Zorom et al., 2013)

Finally, global warming will have an uncertain impact on rainfall in the Sudano-Sahelian region in the next decades (Sultan et al., 2013). This increases the need for risk management options but at the same time makes WII more risky for insurers, thus may raise the insurance premium (Mills 2007). Since our model was also designed to simulate, in a future study, different climate change scenarios, this issue could be addressed in a future work. Weather distributions could be derived from climate change scenarios and different adaptations strategies by farmers could be simulated, distinguishing for instance myopic expectations, in which farmers take decisions on the basis of the past climate, and more forward-looking but not necessarily perfect expectations of the changing climate. 


\section{Acknowledgements}

This study was carried out with support from the French agency for research funding (ANR), within the framework of its 'ESCAPE' project (Environmental and Societal Changes in Africa - Past, Present and Future) and from the GIS Climat Environnement Société, within the framework of its AGECCAO project (Adaptation de l'agriculture et de la gestion de l'eau au changement climatique en Afrique de l'Ouest). Support was also provided by the project 'AMMA2050' (African Monsoon Multidisciplinary Analysis 2050) funded by UK's Department for International Development (DFID) and the Natural Environment Research Council (NERC).

We are grateful to the farmers of the Senegalese groundnut basin who took part in the study by receiving us in their fields and houses and agreeing to devote some of their time to answering our numerous questions.

Finally, we would like to thank two anonymous referees whose comments have allowed us to greatly improve this article, Dr Séraphin G. Dorégo (ISRA) for drawing Figure 1, ISRA-CERAAS and in particular Moustapha Fall for collecting and managing agrometeorological data. 


\section{References}

Affholder, F., 1997. "Empirically modelling the interaction between intensification and climatic risk in semiarid regions." Field Crops Research 52(1/2): 79-93.

Affholder, F., Poeydebat, C., Corbeels, M., Scopel, E., Tittonell, P., 2013. The yield gap of major food crops in family agriculture in the tropics: assessment and analysis through field surveys and modelling. Field Crops Research 143, 106-118.

Affholder, F., Tittonell, P., Corbeels, M., Roux, S., Motisi, N., Tixier, P., Wery, J., 2012. Ad Hoc Modeling in Agronomy: What Have We Learned in the Last 15 Years? Agron. J. 104, 735-748.

Albergel, J., Perez, P., Vaksmann, M., 1991. Amélioration des modèles de bilan hydrique sur parcelle par la prise en considération des états de surface. In: M.V.K. Sivakumar, J.S.W., C. Renard and C. Giroux (Editors) (Ed.), Soil water balance in the Sudano-Sahelian zone. International Association of Hydrological Science, Niamey, Niger, pp. 483-496.

Badiane, A.N., Khouma, M., Sène, M., 2000a. Gestion et transformation de la matière organique: synthèse des travaux de recherches menés au Sénégal depuis 1945. ISRA, Dakar, Sénégal.

Badiane, A.N., Khouma, M., Sène, M., 2000b. Région de Diourbel: Gestion des sols. Drylands Research Working Papers, Somerset, UK.

Baron, C., 1991. Exploitation d'enquêtes en milieu paysan pour une approche agroclimatique du rendement du mil. Base de données PRODCLIM. In: CIRAD-CA (Ed.), Montpellier, p. 60 p.

BCEAO (Banque centrale des Etats de l'Afrique de l'ouest), 2012. Rapport sur la situation de la pauvreté dans les pays de l'UMEOA. Dakar, Sénégal,

http://www.bceao.int/Rapport-sur-la-situation-de-la.html

Bebbington A., 1999. Capitals and capabilities: A framework for analyzing peasant viability, rural livelihoods and poverty. World Development, Vol. 27, № 12, pp. 2021-2044, 1999.

Benoit-Cattin, M., 1986. Recherche et développement agricole: les unités expérimentales du Sénégal. Montpellier, France, ISRA, CIRAD, FAC.

Berg, A., Quirion, P., Sultan, B., 2009. Weather-Index Drought Insurance in Burkina-Faso: Assessment of Its Potential Interest to Farmers. Weather, Climate \& Society 1, 71-84.

Bertram-Huemmer, V. and K. Kraehnert, 2015. Does Index Insurance Help Households Recover from Disaster? Evidence from IBLI Mongolia. DIW Berlin Discussion Papers 1515.

Binswanger-Mkhize, H. P., 2012. "Is there too much hype about index-based agricultural insurance?" Journal of Development Studies 48(2): 187-200.

Blazy, J.M., Ozier-Lafontaine, H., Doré, T., Thomas, A., Wery, J., 2009. A methodological framework that accounts for farm diversity in the prototyping of crop management systems. Application to banana-based systems in Guadeloupe. Agricultural Systems 101, 30-41.

Boulier, F. and P. Jouve, 1990. Evolution des systèmes de production sahéliens et leur adaptation à la sécheresse. Montpellier, France, R3S-CILSS-CIRAD.

Boussard, J.M., J.J. Daudin, 1988. La programmation linéaire dans les modèles de production. Actualités scientifiques et agronomiques de I'INRA, INRA, Paris. 
Carter, M. R. and C. B. Barrett 2006. "The economics of poverty traps and persistent poverty: An asset-based approach." The Journal of Development Studies 42(2): 178-199.

Carter, M. R., Cheng, L., \& Sarris, A., 2016. Where and how index insurance can boost the adoption of improved agricultural technologies. Journal of Development Economics, 118, 59-71

Cole, S., X. Giné, et al., 2013. "Barriers to Household Risk Management: Evidence from India." American Economic Journal: Applied Economics 5(1): 104-135.

De Nicola, F., 2015. The impact of weather insurance on consumption, investment, and welfare. Quantitative Economics 6, 637-661.

Elabed, G., \& Carter, M. R., 2014. Ex-ante impacts of agricultural insurance: Evidence from a field experiment in Mali. University of California at Davis

Fall, S.T., Fall, A.S., Cissé, I., Badiane, A., Fall, C.A., Diao, M.B., 2000. Intégration horticulture-élevage dans les systèmes agricoles urbains de la zone des Niayes (Sénégal). Bulletin de l'APAD.

Forest, F., Cortier, B., 1989. Evaluation et suivi de la production agricole en fonction du climat et de I'environnement. In: CIRAD-IRAT (Ed.), Montpellier, p. 203 p.

Garin, P., A. Faye, et al., 1990. "Evolution du rôle du bétail dans la gestion de la fertilité des terroirs sereer au Sénégal." Les Cahiers de la Recherche Développement 26: 65-84.

Giné, X., D. Karlan, M. Ngatia, 2013. Social networks, financial literacy and index insurance. Working Paper, Mimeo: $17 \mathrm{p}$.

Giné, X., \& Yang, D., 2009. Insurance, credit, and technology adoption: Field experimental evidence from Malawi. Journal of development Economics, 89(1), 1-11

Greatrex H., J. Hansen, S. Garvin, R. Diro, S. Blakeley, M. Le Guen, K. Rao, and D. Osgood, 2015. Scaling up index insurance for smallholder farmers: Recent evidence and insights. CCAFS Report No. 14

Hazell, P. B. and U. Hess, 2010. "Drought insurance for agricultural development and food security in dryland areas." Food Security 2(4): 395-405.

Hill, R. V., J. Hoddinott, et al., 2013. "Adoption of weather index insurance: learning from willingness to pay among a panel of households in rural Ethiopia." Agricultural Economics 44(4-5): 385-398.

HLPE, 2013. Investing in smallholder agriculture for food security. A report by the High Level Panel of Experts on Food Security and Nutrition of the Committee on World Food Security. Rome: $112 \mathrm{p}$.

ISRA, 2008. Caractérisation et typologie des exploitations agricoles familiales du Sénégal, Tome 3, Vallée du fleuve Sénégal. Etudes et documents. 8.

Jacquet F. Butault. J.P. Guichard L., 2011. An economic analysis of the possibility of reducing pesticides in French field crops, Ecological Economics Vol. 70 (9) : 1638-1648

Janssen, S., van Ittersum, M.K., 2007. Assessing farm innovations and responses to policies: A review of bio-economic farm models. Agric. Syst. 94, 622-636

Karlan, D., R. D. Osei, et al., 2014. Agricultural decisions after relaxing credit and risk constraints. Quarterly Journal of Economics 129(2), 597-652. 
Kouakou, P., 2013. Amélioration de la prévision des rendements du mil au Sénégal par l'utilisation de modèles de culture: prise en compte de la sensibilité à la photopériode des variétés et de la fertilité dans les parcelles d'agriculteurs. Université Cheikh Anta Diop, Dakar, Sénégal, p. 105 p.

Leblois, A., P. Quirion, A. alhassane, S. Traoré, 2013. "Weather Index Drought Insurance: An Ex Ante Evaluation for Millet Growers in Niger." Environmental and Resource Economics 57(4): 527-551.

Leblois, A., P. Quirion, B. Sultan, 2014. "Price vs. weather shock hedging for cash crops: ex ante evaluation for cotton producers in Cameroon." Ecological Economics 101: 67-80.

Le Gal, P.-Y., Dugué, P., Faure, G., Novak, S., 2011. How does research address the design of innovative agricultural production systems at the farm level? A review. Agric. Syst. 2011, 714-728.

Lericollais, A., 1972. SOB.: Étude géographique d'un terroir sérer (Sénégal). Paris, France, IRD Editions.

Lhoste, P., 1986. L'association agriculture-élevage. Evolution du système agro-pastoral au SinéSaloum (Sénégal). Maison-Alfort, France, IEMVT-CIRAD.

Louhichi, K., A. Kanellopoulos, S. Janssen, G. Flichman, M. Blanco, H. Hengsdijk, T. Heckelei, P. Berentsen, A. Oude Lansink, M.K. Van Ittersum, 2010. FSSIM, a bio-economic farm model for simulating the response of EU farming systems to agricultural and environmental policies. Agric. Syst., 103, pp. 585-597

Mahul, O., 2012. Agricultural insurance for developing countries. The role of governments. FARMPluriagri Conference on Insuring Agricultural Production. Paris: 17p.

McIntosh, C., A. Sarris, F. Papadopoulos, 2013. "Productivity, credit, risk, and the demand for weather index insurance in smallholder agriculture in Ethiopia." Agricultural Economics 44(4-5): 399417.

Mills, E., 2007. Synergisms between climate change mitigation and adaptation: an insurance perspective. Mitigation and Adaptation Strategies for Global Change, 12(5), 809-842.

Mobarak, A. M. and M. R. Rosenzweig, 2013. "Informal Risk Sharing, Index Insurance, and Risk Taking in Developing Countries." The American Economic Review 103(3): 375-380.

Paas, W., Kanellopoulos, A., van de Ven, G., Reidsma, P., 2016. Integrated impact assessment of climate and socio-economic change on dairy farms in a watershed in the Netherlands. NJAS-Wagen. J. Life Sci. 78, 35-45.

Pieri, C., 1989. Fertilité des terres de savanes: bilan de trente ans de recherche et de développement agricoles au sud du Sahara. Paris, France, Ministère de la coopération et du développement-CIRAD.

Pretty, J., Toulmin, C., Williams, S., 2011. Sustainable intensification in African agriculture. International journal of agricultural sustainability 9, 5-24.

Prudencio, C. Y., 1993. "Ring management of soils and crops in the West African semi-arid tropics: the case of the Mossi farming system in Burkina Faso." Agriculture, Ecosystems \& Environment 47(3): 237-264.

Rosenzweig, M. R. and H. P. Binswanger, 1993. "Wealth, weather risk, and the composition and profitability of agricultural investments." Economic Journal 103(416): 56-78.

Roudier, P., Alhassane, A., Baron, C., Louvet, S., \& Sultan, B., 2016. Assessing the benefits of weather and seasonal forecasts to millet growers in Niger. Agricultural and Forest Meteorology, 223, 168-180 
Sanfo, S., Gérard, F., 2012. Public policies for rural poverty alleviation: The case of agricultural households in the Plateau Central area of Burkina Faso. Agricultural Systems, http://dx.doi.org/10.1016/j.agsy.2012.02.006

Sinclair, T.R., Seligman, N.G., 1996. Crop modeling: from infancy to maturity. Agronomy Journal 88, 698-704.

Sinclair, T.R., Seligman, N.G., 2000. Criteria for publishing papers on crop modeling. Field Crops Research 68, 165-172.

Tadesse, M. A., Shiferaw, B. A., \& Erenstein, O., 2015. Weather index insurance for managing drought risk in smallholder agriculture: lessons and policy implications for sub-Saharan Africa. Agricultural and Food Economics, 3(1), 1-21

Sultan, B., P. Roudier, P. Quirion, A. Alhassane, B. Muller, M. Dingkuhn, P. Ciais, M. Guimberteau, S. Traore and C. Baron, 2013. Assessing climate change impacts on sorghum and millet yields in the Sudanian and Sahelian savannas of West Africa. Environmental Research Letters 8(1)

Teklewold, H., Kassie, M., Shiferaw, B., \& Köhlin, G., 2013. "Cropping system diversification, conservation tillage and modern seed adoption in Ethiopia: Impacts on household income, agrochemical use and demand for labor." Ecological Economics 93: 85-93.

The Montpellier Panel, 2013. Sustainable Intensification: A New Paradigm for African Agriculture. London: 36 p.

World Bank, 2008. Agriculture for development: World Development Report. Washington DC, World Bank: 386 p.

Zorom, M., Barbier, B., Mertz, O., Servat, E., 2013. Diversification and adaptation strategies to climate variability: A farm typology for the Sahel. Agric. Syst. 116, 7-15. 


\section{Appendix A. Farm typologies, Dendrogram and Calinski-Harabasz index}

The number of farm-types was chosen based on dendrogram observation (Fig A1 and A2) and the Calinski-Harabasz criterion (Table A1). The Calinski-Harabasz criterion is defined as $\frac{S S_{B}}{S S_{W}} \frac{N-k}{k-1}$ where $S S_{B}$ is the between-cluster variance, $S S_{W}$ the within-cluster variance, $N$ the number of observations and $k$ the number of clusters. The higher the index, the best the clustering quality. We kept 3 farm-types in each subzone because i) with more farm-types the observed farming system heterogeneities represented would have been too similar to one another to be reproduced through modeling, and ii) the classes across the two subzones share common characteristics, thus facilitating their description and the interpretation of the model outputs.

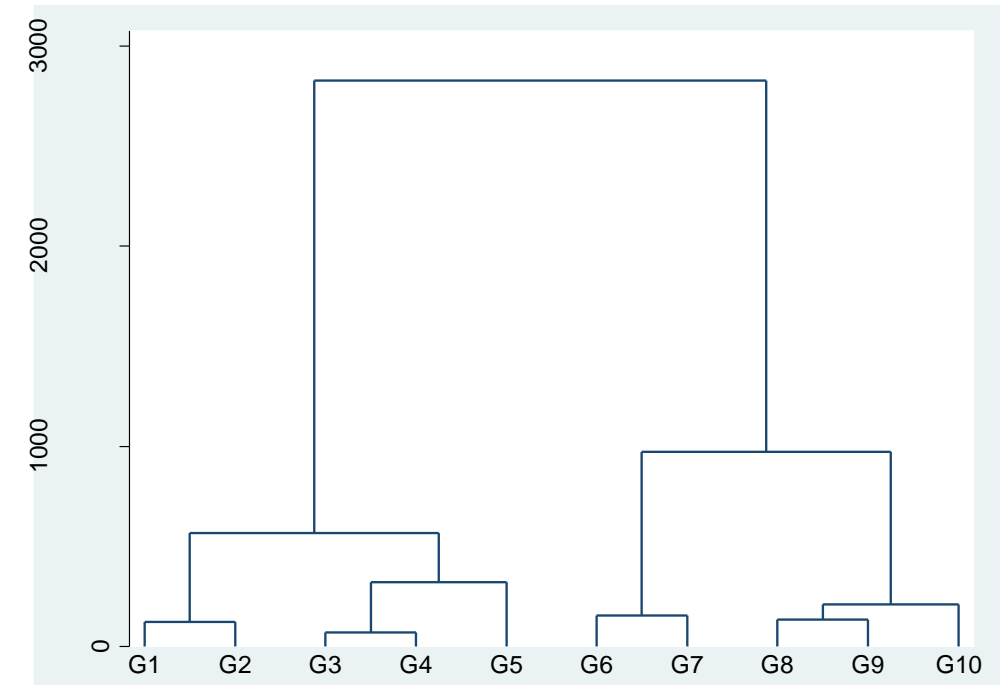

Fig. A1: Dendrogram truncated after tenth level - Sine

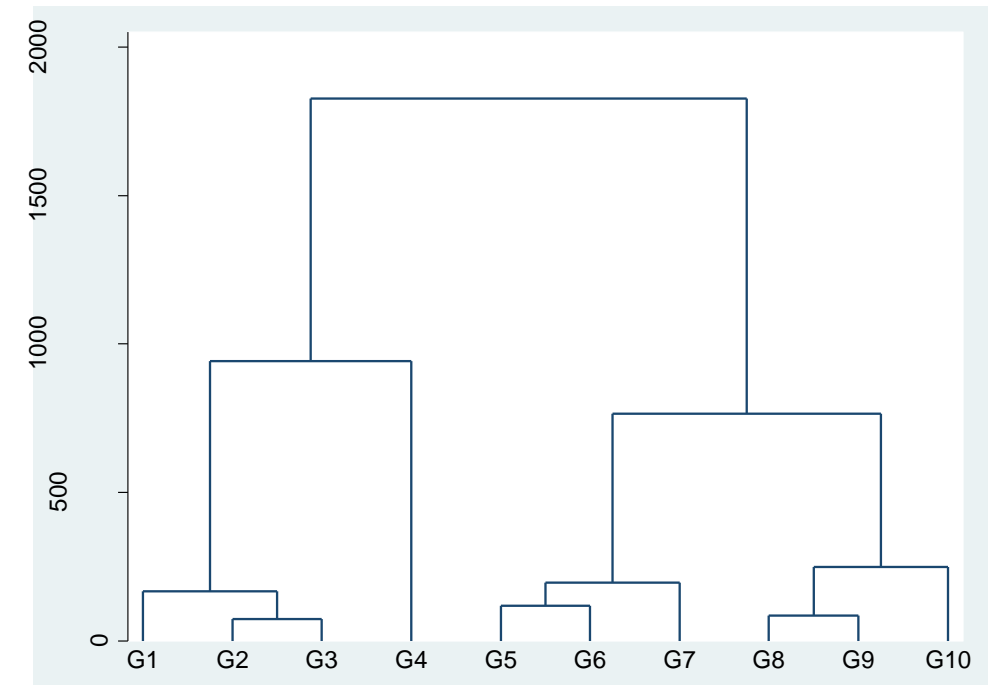

Fig. A2: Dendrogram truncated after tenth level - Saloum 
Table A1 Calinski-Harabasz criterion depending on the number of cluster (left: Sine; right: Saloum)

\begin{tabular}{ll}
\hline Number of farm-types & Calinski-Harabasz criterion \\
\hline 2 & 69.42 \\
3 & 64.64 \\
4 & 63.95 \\
5 & 61.5 \\
6 & 58.78 \\
7 & 56.52 \\
8 & 55.62 \\
9 & 55.59 \\
10 & 53.51 \\
\hline (Sine subzone) &
\end{tabular}

\begin{tabular}{ll}
\hline Number of farm-types & Calinski-Harabasz criterion \\
\hline 2 & 47.44 \\
3 & 49.26 \\
4 & 60.32 \\
5 & 56.22 \\
6 & 54.17 \\
7 & 53.68 \\
8 & 52.57 \\
9 & 50.86 \\
10 & 49.6 \\
\hline
\end{tabular}

(Saloum subzone) 
Appendix B. Average yield and coefficient of variation, by cropping system

\begin{tabular}{|c|c|c|c|c|c|}
\hline & & \multicolumn{2}{|c|}{ Mean yield $\left(\mathrm{kg} \mathrm{ha}^{-1}\right)(1991-2010)$} & \multicolumn{2}{|c|}{ Coefficient of variation } \\
\hline & & Sine & Saloum & Sine & Saloum \\
\hline \multirow{2}{*}{ MilExt } & Homefield & 1175 & 1131 & 14 & 12 \\
\hline & Bushfield & 524 & 422 & 10 & 5 \\
\hline \multirow{2}{*}{ MilManu } & Homefield & 1756 & 1709 & 19 & 20 \\
\hline & Bushfield & 1251 & 1130 & 14 & 13 \\
\hline \multirow{2}{*}{ MilFert } & Homefield & 2006 & 1983 & 22 & 24 \\
\hline & Bushfield & 1589 & 1450 & 17 & 18 \\
\hline \multirow{2}{*}{ MilManuFert } & Homefield & 2167 & 2216 & 25 & 18 \\
\hline & Bushfield & 2167 & 2216 & 25 & 18 \\
\hline \multirow{2}{*}{ MaizeFert } & Homefield & 2050 & 2217 & 13 & 20 \\
\hline & Bushfield & 1865 & 1934 & 14 & 17 \\
\hline \multirow{2}{*}{ MaizeManuFert } & Homefield & 2127 & 2335 & 14 & 21 \\
\hline & Bushfield & 2127 & 2335 & 14 & 21 \\
\hline \multirow{2}{*}{ GroundnutExt } & Homefield & 828 & 817 & 11 & 7 \\
\hline & Bushfield & 592 & 558 & 9 & 6 \\
\hline \multirow{2}{*}{ GroundnutManu } & Homefield & 965 & 950 & 13 & 8 \\
\hline & Bushfield & 726 & 686 & 10 & 6 \\
\hline \multirow{2}{*}{ GroundnutFert } & Homefield & 990 & 971 & 15 & 9 \\
\hline & Bushfield & 708 & 670 & 11 & 7 \\
\hline
\end{tabular}

2

3 
1 Appendix C: The crop dynamic simulation model CELSIUS (CEreal and Legume crops Simulator Under Sahelian Environment): Conceptual and mathematical description

Part I. General description and credits to other models.

CELSIUS (CEreal and Legume crops SImulator Under changing Sahelian environment) is a simulation model and as such it has a conceptual form (i.e. a schematic representation of the system simulated with the main variables and relationships between variables, a mathematical form i.e. the list of mathematical equations of the model, and a software form, the latter with the code expressed in a programming language as well as in a compiled, executable file. In the present document, we provide a simplified conceptual description and a commented, mathematical form of the model. The only exact description of the simulation model, however, is its un-compiled software form, which is available on request at francois.affholder@cirad.fr, and was written using Microsoft Visual Basic for Application under Microsoft Access, using the principles of interfacing between models and databases in order to facilitate virtual experiments (Affholder et al., 2012).

CELSIUS consists on the previously published model PYE (Potential Yield Estimator - (Affholder et al., 2013)) plus a number of additions, with a system of simulation options allowing, among other possible combinations, to choose to simulate a crop exactly as PYE would do, or to use all the components forming CELSIUS.

Thus CELSIUS allows simulating crop development and growth, total above ground biomass at harvest $(A G B)$ and grain yield $(Y)$ under, depending on the simulation option chosen, the typical potential and limiting conditions corresponding to the concept of yield gap (Van Ittersum and Rabbinge, 1997; van Ittersum et al., 2013). More precisely, CELSIUS simulates AGBO and YO which are respectively total above ground biomass and yield under potential conditions (no limitation other than temperature and radiation), AGBw and $Y w$ corresponding to the same variables under water limiting conditions (rainfall limitation added to the potential conditions), AGBn and $\mathrm{Yn}$ under nitrogen limiting conditions (nitrogen limitation added to the potential conditions) and also AGBwn and Ywn under nitrogen and water limiting conditions (nitrogen and rainfall limitations added to the potential conditions).

CELSIUS runs on a daily time step and takes its whole crop development and growth module from STICS (Brisson et al., 1998; Brisson et al., 2003). Seed germination and crop emergence are calculated as a single phase controlled by thermal time and water content of the topsoil. Crop phenology and potential leaf area index (LAIO) are simulated as determined by photo-thermal time. 
Except the calculation of runoff, taken from Albergel et al. (1991) and the effect on soil evaporation and runoff of a mulch of straw residues, taken from Scopel et al. (2004), its whole water balance module comes from Sarra (Forest and Clopes, 1994; Affholder, 1997), also used in the more recent version of the model, Sarrah (Dingkuhn et al., 2003). The water balance module of Sarra is based on the classical 'tipping bucket' approach (van Keulen, 1975) and is very similar to the one used in STICS, hence the possibility to consistently couple the Sarra water balance module with the crop module of STICS while reusing many standard parameters of the latter. The water balance accounts for the interaction between root growth and the seasonal descent of the wetting front of the soil, a feature that proved to significantly affect crop growth in tropical environments with a relatively long dry season and where the soil profile is generally at or below wilting point at the onset of the cropping season (Affholder, 1995). Runoff is computed following the approach of Sissoko (2009). The latter combines the runoff model from Albergel et al. (1991) based on the interaction between the time sequence of daily rainfall and soil crusting, according to a typology of soil crusting sensitivity, and a model of the impact on runoff of a straw mulch decaying over time as in Scopel et al. (2004). Soil evaporation is reduced in case of the presence of a straw mulch following Scopel et al. (2004) or of a plastic film following Luu Ngoc Quyen (2012). A water stress coefficient is computed as a bilinear function of the fraction of transpirable soil water (FTSW) with a threshold parameter as in Allen et al. (1998).

A nitrogen stress coefficient is computed using a simple seasonal estimate of $\mathrm{N}$ available in soil from mineralization of soil organic matter, mineralization of a decaying biomass added to the soil, $\mathrm{N}$ inorganic fertilizers inputs, and symbiotic fixation of atmospheric $\mathrm{N} 2$, with a coefficient of $\mathrm{N}$ losses through $\mathrm{N}$-leaching and volatilization. The nitrogen stress coefficient is a bilinear function of $\mathrm{N}$ available in soil, with a threshold parameter corresponding to the level of $\mathrm{N}$ available in soil above which $\mathrm{N}$ is not limiting crop growth. This approach of the relationship between $\mathrm{N}$ availability and yield reduction relatively to a potential yield is a simplification of the relationships used in the model Field (Tittonell et al., 2010) or Quefts (Janssen et al., 1990), especially by assuming that P and K limitations as well as interactions of soil $\mathrm{pH}$ with $\mathrm{N}$ availability are all constant across the set of situations to be simulated.

Under stress resulting from water-limiting or nitrogen limiting conditions, potential daily increase in leaf area index during vegetative growth is multiplied by a stress coefficient which is the lowest value of the water and nitrogen stress coefficients. During post flowering development phases, LAI decrease is accelerated by stresses. 
Daily global solar radiation is intercepted by the resulting leaf area index following a beer law

2 with an extinction coefficient, and converted into biomass following a net conversion efficiency

3 approach, the potential efficiency being reduced by temperature below or above an optimum, and

4 by water or nitrogen stress. $\mathrm{CO} 2$ concentration of the atmosphere increases conversion efficiency by

5 a coefficient depending on the C3 or C4 type of the crop. A part of the accumulated dry matter is

6 allocated to grain following an harvest index approach coupled with a sink limitation accounting for

7 thermal or water stress during a fruit-forming sensitive stage (Brisson et al., 1998).

8 Sowing date can be simulated as the first date at which the amount of daily rainfall exceeds a

9 certain threshold, within a certain interval of dates. The crop can be killed by extreme stress and a new sowing can automatically be computed using the same decision rule. 


\section{Part II. Detailed mathematical description}

\section{Modelling Options}

See OptionModelClass in the software code.

A number of Boolean Variables (having 'True' or 'False' as the only possible values) are used to set modelling options.

\section{These are Simlevee, CyberST, ActiveStressH, ActivestressN, and CorAlti}

If Simlevee is True then germination plus emergence are simulated, else they are forced to input values.

If CyberST is True then sowing, germination and emergence are simulated otherwise sowing is set to input value and germination plus emergence are accounted for according to the value of SimLevee

If ActiveStressH is True then water stress is used to reduce growth ( $\mathrm{Yw}$ or Ywn calculated according to setting of ActiveStress $N$ ), else water stress is still calculated but has no impact on growth calculation ( $\mathrm{YO}$ or $\mathrm{Yn}$ calculated according to setting of ActiveStress $N$ ). Whatever its setting ActiveStressH has no Impact on germination plus emergence or on crop survival due to extreme water stress.

If ActiveStress $N$ is True then nitrogen stress is used to reduce growth ( $\mathrm{Yn}$ or $\mathrm{Ywn}$ calculated according to setting of ActiveStressH), else nitrogen stress is still calculated but has no impact on growth calculation (YO or Yw calculated according to setting of ActiveStressH)

If CorAlti is True then Temperature is corrected according to difference of elevation between weather station and simulated plot else temperature from weather station is applied.

\section{Plant development and growth}

\section{1.- Crop emergence}

See PlanteClass. GerminLevee in the software code.

A day $n$ after the starting day of the simulation is the day of crop emergence if the thermal time accumulated since the day of sowing jsow, discounting days with soil moisture below a certain threshold, exceeds a cultivar- dependent thermal time constant CTger as follows: 


$$
\text { If } \sum_{j=j s o w}^{n} \min ((\operatorname{Tm}(j)-\text { Tger }) \times W \text { ConstGer }(j) ; 0) \geq \text { CTger then Jlev }=n
$$

1

With:

$n$ : current day of simulation,

jsow: day of sowing,

$\operatorname{Tm}(j)=$ mean temperature of day $\mathrm{j}$,

Tger= cultivar dependent, min temperature for accumulation of thermal time during germination + emergence phase,

Jlev= day of emergence,

WConstGer(j): water constraint applied to germination plus emergence, for day $j$. Integer, value 1 (soil water not constraining germination or emergence) or 0 (soil water constraining germination or emergence), calculated in equation CELSIUS.21.

\subsection{Crop development}

See PlanteClass. phenoCTphot in the software code

Five development stages are considered. A day $n$ after starting day of the simulation is the day of completion of a certain stage $i$ if the accumulated photo-thermal time since the preceding stage corresponds to the thermal constant of stage $i$, as in the following equation:

Equation CELSIUS.2

$$
\text { If } \sum_{j=D s t g e(i-1)+1}^{n} \operatorname{PhotFact}(j) \times(f(\operatorname{Tm}(j))) \geq C T(i) \text { then Dstge }(i)=n
$$

With:

$i \in[1 ; 6] \cap \mathbb{N} ; n \in \mathbb{N} ; j \in \mathbb{N} ; f:$ function defined as:

$$
\begin{gathered}
\text { If } \operatorname{Tm}(j) \leq t \text { dmin then } f(\operatorname{Tm}(j))=0 \\
\text { If } \operatorname{tdmin}<\operatorname{Tm}(j) \leq t d \max \text { then } f(\operatorname{Tm}(j))=\operatorname{Tm}(j)-t d \min
\end{gathered}
$$




$$
\text { If } \operatorname{Tm}(j)>t d m a x \text { then } f(\operatorname{Tm}(j))=t d \max -t d \min
$$

1

And

$$
\begin{gathered}
\text { If }(i \neq 2 \text { OR } D L(j)<M O P P) \text { then PhotFact }(j)=1 \\
\text { If } i=2 \text { AND } D L(j) \geq M O P P \text { then } \\
\text { PhotFact }(j)=1-(D L(j)-M O P P) \times \text { SensPhot }
\end{gathered}
$$

2

Where:

Dstge(i): day of completion of stage i; Positive integer, Dstge(0)= Jlev

CT(i): thermal time accumulated for completing stage i

tdmin: base temperature for thermal time accumulation

tdmax: maximal temperature for thermal time accumulation

$D L(j):$ photoperiod (astronomic diurnal duration) of day $\mathrm{j}$

MOPP: threshold of photoperiod above which cultivar has its development rate reduced by photoperiod.

SensPhot: Coefficient of sensitivity of cultivar to photoperiod

PhotFact: reduction coefficient applied to development rate when when affected by photoperiod

\subsection{Leaf Area Index (LAI)}

See PlanteClass. Calcule_LAI_SemiAride in the software code

LAI on day $n$ ( $\operatorname{LAI}(n)$ is computed by adding dlai( $n$ ), a daily increase (or decrease if negative), of LAI to the LAI of the previous day $(n-1)$.

a) During development stages 1 and 2, daily increase of LAI (dLAI(n)) for a day $n$ is calculated using equations taken from STICS as follows:

Equation CELSIUS.3

$$
d \operatorname{LAI}(n)=\frac{\text { dlaimax }}{1+\exp (5.5 *(\text { Vlaimax }-\operatorname{Ulai}(n))} \times f(\operatorname{Tm}(n)) \times \operatorname{LAIStress}(n) \times \Delta \operatorname{idens}(\operatorname{denspl})
$$


With

$$
\begin{gathered}
\text { during stage 1: Ulai }(n)=1+(\text { Vlaimax }-1) \times N T T(n) ; \\
\text { During stage 2: Ulai }(n)=\text { Vlaimax }+(3-\text { Vlaimax }) \times N T T(n)
\end{gathered}
$$

3

$$
\text { For a stage } i, \quad \operatorname{NTT}(n)=\sum_{j=D \text { stge }(i-1)+1}^{n} \operatorname{PhotFact}(j) \times(f(\operatorname{Tm}(j))) / \operatorname{CT}(i)
$$

4

5

And

$$
\begin{aligned}
& \text { If } \operatorname{LAI}(n)>\text { LAIComp And Densplt }>\text { bdens then } \Delta \text { idens }(\text { denspl }) \\
& \qquad=\text { densplt } \times\left(\frac{\text { densplt }}{\text { bdens }}\right)^{\text {adens }} \text { else } \Delta \text { idens }(\text { denspl })=\text { densplt }
\end{aligned}
$$

Where

$f(\operatorname{Tm}(n))$ is the same function as in equation CELSIUS.2

dLAImax: maximum daily increase of LAI

Vlaimax is a general parameter defining the slope at inflexion point of dLAl as a function of thermal time.

densplt, stand density

Ulai(n) leaf development unit (equal to Vlaimax at inflexion point of dlai(n), equal to 3 at end of stage 2)

$N T T(n):$ normalized thermal time

LAIcomp: LAI threshold above which competition between plants for light occurs

Didens: effect of stand density on LAI

bdens: cultivar dependant stand density threshold above which leaf area per plant is influenced by stand density

adens: cultivar dependant parameter defining the sensitivity to stand density of leaf area per plant when stand density is above bdens 
2 stress occurs), calculated in equation CELSIUS.31

b) During development stage i among stages 3 to 5 (senescence of leaves accelerated by stress) LAI dynamics is simulated as follows:

$$
d \operatorname{LAI}(n)=\{\Delta \text { LAIpot }-(\operatorname{SensSen} \times(1-\operatorname{LAIstress}(n) \times \operatorname{LAI}(n-1))\} \times f(\operatorname{Tm}(n))
$$

With

During stages 3 and 4 no senescence occurs in the absence of stress: $\Delta$ LAIpot $=0$

$$
\text { During stage 5: } \Delta \text { LAIpot }=(\text { LaiRec }- \text { Lai }(\text { Dstge }(4))) / C T(5)
$$

7

And:

SensSen: cultivar dependent sensitivity coefficient for leaf senescence accelerated by stress LaiRec: cultivar dependent potential value (in the absence of any stress) of LAI at maturity SLAIpot: potential average decrease of LAl after stage 2 , in the absence of stress

\subsection{Above Ground Biomass}

See PlanteClass.biomassein the software code

Intercepted solar radiation $\operatorname{raint}(n)$ for a day $n$ is given by:

Equation CELSIUS.5 (taken from STICS)

$$
\operatorname{raint}(n)=0.95 * \operatorname{ParSur} R g * R g(n) *(1-\operatorname{Exp}(-\operatorname{kext} \times \operatorname{Lai}(n))
$$

Where:

ParSurRg is the ratio of photosynthetically active over total global solar radiation $R g(n)$ is global solar radiation of day $n$ kext: a cultivar-dependent extinction coefficient. 
Total aboveground biomass of day $\mathrm{n}(\operatorname{Biom}(n))$ is computed by adding $d \operatorname{Biom}(n)$, the daily increase of biomass, to $\operatorname{Biom}(n-1)$.

$\mathrm{dBiom}(\mathrm{n})$ is calculated using the following equation taken from STICS:

Equation CELSIUS.6

$\operatorname{dBiom}(n)=\operatorname{CO} 2$ fact $\times \operatorname{BiomStress}(n) \times\left(\operatorname{Ebmax} \times \operatorname{raint}(n)-0.0815 \times \operatorname{raint}(n)^{2}\right)$

With:

$$
\text { Co2fact }=2-\operatorname{Exp}(\operatorname{Ln}(2-\operatorname{alphaCO2})) \times(C O 2 c-350) /(600-350))
$$

Where:

$\mathrm{CO} 2 \mathrm{c}$ is the atmospheric concentration of $\mathrm{CO}_{2}$ at the time of the simulation

alphaCO2 is a cultivar dependant coefficient, mostly accounting for the C3 (alphaCO2=1.2) or C4 (alphaCO2=1.1) type of photosynthesis cycle of the species.

Ebmax is the cultivar dependent maximum efficiency of net conversion of intercepted photosyntetically radiation into biomass

$\operatorname{BiomStress}(n)$ is the stress coefficient applied to Biomass ( 0 when stress is maximal, 1 when no stress occurs), calculated using equation CELSIUS.31

\subsection{Grain yield}

See PlanteClass. Rendement in the software code

Grain yield is calculated using equations taken from STICS

A non sink limited harvest index $H I(n)$ on day $n$ linearly increases with time at a cultivar dependent rate Vitircarb, starting at the first day of stage 4 and ending at maturity (DayStge(5)), and with a cultivar dependent ceiling value HImax, following the two equations below:

Equation CELSIUS.7:

$$
\begin{gathered}
\text { if } n>\text { DayStge(3) And } n \leq \text { DayStge(5) then } \\
H I(n)=\operatorname{Min}(\text { Vitircarb } \times(n-\operatorname{DayStge}(3)+1) ; H \operatorname{Imax})
\end{gathered}
$$


When calculating final grain yield $Y$, sink limitation may occur due to a cultivar dependent ceiling value of the weight of 1 grain, P1gmax, and a grain number Ngrains, limited by possible stress impacting average growth rate Vitmoy during a Nbjgrain number of days preceding grain filling stage (starting a DayStge(3)), as follows:

Equation CELSIUS.8:

$$
Y=\operatorname{Min}(H I(\text { DayStge(5)); P1gmax } \times \text { Ngrains })
$$

With

$$
\text { Ngrains }=\text { Cgrain } \times \text { Vitmoy }+ \text { Cgrainv } 0
$$

And

$$
\text { Vitmoy }=(\text { Biom }(\text { DayStge }(3))-\text { Biom }(\text { DayStge }(3)-\text { Nbjgrain })) / \text { Nbjgrain }
$$

Where:

Cgrain and Cgrainv0: cultivar dependant parameters.

\subsection{Root growth}

See PlantClass. Croirac in the model code

Root biomass is not explicitly simulated, but the depth of the rooting zone, $\operatorname{Zrac}(n)$ is dynamically simulated from germination to DayStge(3) with a daily rate of root descent governed by thermal time, limited by the thickness of wet soil below root zone and by a maximal root depth Zracmax, as follows for a day $n$ :

Equation CELSIUS.9

$$
\operatorname{Zrac}(n)=\operatorname{Min}(\operatorname{Zrac}(n-1)+\operatorname{Min}(\operatorname{WZuR}(n-1) ; \operatorname{DeltaRMax} \times f(\operatorname{Tm}(n))) ; \operatorname{Zracmax})
$$

Where:

$W Z u R$ : Thickness of soil below the current root zone having moisture above wilting point (calculated using water balance equations.

DeltaRMAx: cultivar dependent maximal rate of root descent per unit thermal time. 


\section{Mulch or soil - climate interface}

3.1 Mulch biomass (Not used in the study)

See MulchClass. BiomasseMulch in the software code

Equations taken from Scopel et al., 2004.

The biomass of a straw mulch possibly present over the soil's surface, Qpaillis(n), is assumed to decrease with time except in case an amount QpaillisApport(n) is added that day:

Equation CELSIUS.10

$$
\operatorname{Qpaillis}(n)=\operatorname{Qpaillis}(n-1) \times \operatorname{Exp}\left(- \text { Alpha }_{\text {pail }}\right)+\operatorname{QpaillisApport}(n)
$$

Where:

$A l p h a_{\text {pail }}$ : calibration parameter depending on the composition of mulch

An empirical relationship is used to convert Qpaillis(n) into the fraction of soil covered by the straw, FracSoilCover(n):

$$
\operatorname{FracSoilCover}(n)=1-\operatorname{Exp}\left(-\operatorname{Beta\_ pail} \times \operatorname{Qpaillis}(n)\right)
$$

Where

Beta_pail : calibration parameter depending on the composition of mulch

\subsection{Runoff}

See MulchClass. Ruissellement in the software code

The model combines a model from Albergel et al. (1991) for bare soils, with the model of mulch reducing runoff from Scopel et al. (2004), according to the following equation:

\section{Equation CELSIUS.11:}

Water supply $\operatorname{precip}(n)$ (consisting on Rainfall plus Irrigation of the day) is split into runoff Ruis(n) and water infiltrated into the soil and a straw mulch possibly present on the soil's surface, accounting for LAI reducing runoff, a typology of crusting of soil's surface, the biomass of straw 
mulch, and an indicator $I K J(n)$ characterizing the rainfall sequence of the previous days, increasing

2 with the amounts of rainfall and decreasing when the number of days between rainfall events 3 increases:

$$
\begin{aligned}
\operatorname{Ruis}(n)=\operatorname{Max}\left(0 ; \operatorname{Exp}(-0.5 * \operatorname{Lai}(n)) \times\left(\operatorname{Ap} 1+\operatorname{Ap} 3 \times I K J(n)+b_{\text {ruis }} \times \text { Qpaillis }(n)\right)\right. \\
\times(\operatorname{precip}(n)-\text { Seuil_Ruis }))
\end{aligned}
$$

4

With:

$$
I K J(n)=(I K J(n-1)+\operatorname{precip}(n-1)) * \operatorname{Exp}(-0.5)
$$

And

$$
\begin{gathered}
\text { If } A p 1+A p 3 * I K J(n)=0 \text { Then Seuil_Ruis }=0 \\
\text { Else } \\
\text { seuil }=(A p 4-A p 2 \times I K J(n)) /(A p 1+A p 3 \times I K J(n))
\end{gathered}
$$

Where:

b_ruis: a parameter controlling the increase of runoff due to the presence of a straw mulch (generally a negative value, since straw mulch generally decreases runoff)

Ap1...Ap4: empirical coefficients controlling runoff on the part of the soil directly exposed to the impact of rain drops. When Ap2...Ap4 are set to zero, Ruis(n) is a constant proportion bruis of the share of daily rainfall exceeding a threshold Seuil_Ruis, equal to Ap1 in this particular case. When Seuil_Ruis is set to zero and Ap1...Ap4 are non zero, these coefficients correspond to a typology of soil surface status as in Casenave and Valentin $(1989 ; 1992)$ as follows:

\begin{tabular}{llllll} 
Soil surface type & $\begin{array}{l}\text { Vesicular } \\
\text { porosity }\end{array}$ & Ap1 & Ap2 & Ap3 & Ap4 \\
\hline $\begin{array}{l}\text { 1: no crust or predominant } \\
\text { structural crust with remnant }\end{array}$ & $<5 \%$ & 0.2 & 0.03 & 0.004 & 3 \\
$\begin{array}{l}\text { aggregates } \\
\text { 2: runoff crust covering less } \\
\text { area than structural crust }\end{array}$ & $5-30 \%$ & 0.35 & 0.04 & 0.004 & 3 \\
3: runoff crust predominating & $>30 \%$ & 0.900 & 0.05 & 0.002 & 10 \\
\hline
\end{tabular}

Water available for infiltration into soil and the porosity of the straw mulch is $W_{-} S M(n)$ :

Equation CELSIUS.12 


$$
W \_S M(n)=\operatorname{Precip}(n)-\operatorname{Ruis}(n)
$$

1

2

\subsection{Water stored into a porous straw mulch and evaporated (not used in the study)}

See MulchClass. BilanMulch in the software code

Equations taken from Scopel et al., 2004.

Straw mulch is assumed to have a certain capacity CapacityMulch, per unit o mulch biomass, for storing water, the corresponding reservoir Stmulch being updated on a day $n$ as follows:

Equation CELSIUS.13

$$
\begin{aligned}
\operatorname{Stmulch}(n)= & \operatorname{Min}(\text { Qpaillis }(n) \times \text { CapacityMulch; Stmulch }(n-1)-\operatorname{Emulch}(n) \\
& +\operatorname{FracSoilCover}(n) \times W_{\_} \operatorname{SM}(n)
\end{aligned}
$$

Where:

$\operatorname{Emulch}(n)$ is the amount of water lost by mulch on day $n$ by evaporation

The water available for soil infiltration Win(n) is the part of W_SM(n) not stored in Stmulch(n)

Potential evaporation $\operatorname{EoSM}(n)$ at the top of the straw mulch is calculated on a day $n$ assuming that reference Penman-Monteith potential evaporation $\operatorname{ETP}(n)$ is reduced by LAI using an extinction law analogy as follows:

Equation CELSIUS.14

$$
\operatorname{EoSM}(n)=\operatorname{Etp}(n) \times \operatorname{Exp}(-(k e x t-0.2) \times \operatorname{Lai}(n))
$$

Potential evaporation applied to mulch, $\operatorname{EoMulch}(n)$ is calculated as follows:

Equation CELSIUS.15

$$
\operatorname{EoMulch}(n)=\operatorname{EoSM}(n) \times\left(1-\operatorname{Exp}\left(-\operatorname{gamma}_{m u l c h} * \operatorname{Qpaillis}(n)\right)\right)
$$

Where:

Gamma_mulch is a calibration coefficient depending on the species constituting the straw mulch. 


$$
\operatorname{Emulch}(n)=\operatorname{Max}(\operatorname{Stmulch}(n-1) ; \operatorname{Max}(\operatorname{EoMulch}(n) ; \operatorname{Edecomp}(n)))
$$
previous day:

$$
\operatorname{Edecomp}(n)=\operatorname{Stmulch}(n-1) \times(\text { Qpaillis }(n-1)-\operatorname{Qpaillis}(n))) / \operatorname{Qpaillis}(n)
$$

5

\section{Soil water balance}

\subsection{Soil moisture}

See SolClass.EauSol in the software code

The soil moisture model is taken from SarraMillet (Affholder, 1997)

Four main water reservoirs are accounted for dynamically, all having a water storage capacity calculated as the product of the thickness of the reservoir and a total available water per unit thickness TAW, the latter being constant throughout the soil, and calculated as follows:

Equation CELSIUS.17

$$
T A W=(h \min -h c c) * d a
$$

Where:

hmin and hcc: soil water content respectively at wilting point and at field capacity (in mass of water per mass of soil)

$d a$ : soil bulk density

The four mains water reservoirs are the following:

Stger, with a constant thickness Zger and starting at topsoil: contains the water impacting germination and seedlings growth until crop emergence. 
Stsurf with a constant thickness Zsurf and starting at topsoil: contains the water impacting soil evaporation.

Strac with a dynamic thickness Zrac and starting at topsoil, calculated by equation CELSIUS.9, contains the water impacting crop transpiration, i.e. the transpirable soil water.

Stdeep with a dynamic thickness Zsol-Zrac, starting immediately below Zrac and ending at soil maximum depth Zsol.

More specifically three accessory reservoirs Stnonrac (thickness=Zracmax-Zrac), Stmes (Zmes), and StTot (Zsol) are calculated using the same principle, allowing calculation of drainage below the part of soil actually explored by roots at the end of root growth period, comparisons of simulated soil water with measurements performed down to a depth Zmes possibly differing from Zsol, and the calculation of the overall soil balance (StTot being the sum of Strac and Stnonrac).

For any of these reservoirs, noted generically Stres(n) or a reservoir of thickness Zres, the water balance accounting for soil evaporation $\operatorname{Esol}(n)$ and crop transpiration Transpi( $n)$ is calculated as follows for a day $n$ :

Equation CELSIUS.18

$$
\begin{aligned}
\operatorname{Stres}(n)= & \operatorname{Max}(\operatorname{Min}(\operatorname{Stres}(n-1)+\operatorname{WIn}(n)-\operatorname{Esol}(n) \times \operatorname{CEres}-\operatorname{Transpi}(n) \times \operatorname{TEres} ; \operatorname{TAW} \\
& \times \operatorname{Zres}) ; 0)
\end{aligned}
$$

Where:

CEres and TEres are coefficients distributing Evaporation and transpiration among the reservoirs as follows:

CEres=1 in Stsurf, Zger/Zsurf in Stger, Zrac/zsurf until zrac is greater than Zsurf in Strac, and 0 in Stdeep

TEres $=$ Zrac/Zsurf, in Stsurf until Zrac overcomes Zsurf, Zsurf/Zrac afterwards, Zrac/Zger in Stger until Zrac overcomes Zger, Zrac/Zger afterwards, 1 in Strac, and 0 in Stdeep

And:

$W \operatorname{In}(n)$ is water input into the reservoir, corresponding to the drainage from the reservoir immediately above if applying or corresponding to water from irrigation or rainfall infiltrated into the soil. 
$$
\operatorname{Dres}(n)=\operatorname{Max}(0 ; \text { TAW } \times \operatorname{Zres}
$$$$
-(\operatorname{Stres}(n-1)+W \operatorname{In}(n)-\operatorname{Esol}(n) \times \text { CEres }- \text { Transpi }(n) \times \text { TEres }))
$$

Water $\operatorname{Dres}(n)$ drained out of a reservoir is calculated as the amount of water exceeding the storage capacity of the reservoir when calculating the balance, as follows:

$$
\text { Equation CELSIUS.19 }
$$

4

Water constraint $W C \operatorname{Cres}(n)$ is calculated for a reservoir $\operatorname{Stres}(n)$ as the ratio of actual water content of the reservoir over its storage capacity as follows:

Equation CELSIUS.20

$$
\operatorname{WCres}(n)=\operatorname{Stres}(n) /(T A W \times Z r e s)
$$

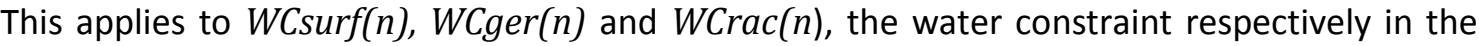
surface reservoir (water constraint reducing evaporation relatively to potential evaporation), in the germination plus emergence reservoir and the root zone reservoir (limiting transpiration relatively to potential).

The factor WConstGer( $n)$ in equation CELSIUS.1, delaying germination and emergence in the reservoir $\operatorname{Stger}(n)$ is calculated from $W \operatorname{Cger}(n)$ as follows:

Equation CELSIUS.21

$$
\text { If } W \operatorname{Cger}(n)>0 \text { then } W \operatorname{ConstGer}(n)=1 \text { Else WConstGer }(n)=0
$$

\subsection{Soil evaporation}

See SolClass. Evaporation in software code

Potential soil evaporation $\operatorname{Eos}(n)$ is calculated accounting from the reduction of energy reaching soil surface due to the presence of leaves and a straw mulch as follows:

Equation CELSIUS.22:

$$
\operatorname{Eos}(n)=\operatorname{EoSM}(n)-\operatorname{EoMulch}(n)
$$

Soil evaporation $\operatorname{Esol}(n)$ on a day $n$ is calculated as follows:

Equation CELSIUS.23: 


$$
\begin{gathered}
\text { if } \operatorname{WCSurf}(n) \geq \operatorname{SeuilEvap} \text { Then } \operatorname{Esol}(n)=\operatorname{Eos}(n) \\
\text { if } W \operatorname{Csurf}(n)<\operatorname{SeuilEvap} \text { Then } \\
\operatorname{Esol}(n)=\operatorname{Eos}(n) * \operatorname{WCSurf}(n) / \operatorname{SeuilEvap}
\end{gathered}
$$

2

Where:

SeuiEvap: soil dependent calibration parameter

\subsection{Crop transpiration}

See CultureClass.CalcTranspiMC in the software code

Potential evapotranspiration is calculated using a crop coefficient $K C(n)$ approach taken from STICS, in which $K c(n)$ is calculated with an empirical relationship between $K c(n)$ and $\operatorname{LAI}(n)$, and taken as follows:

Equation CELSIUS.24

$$
K c(n)=(1+(\operatorname{Kmax}-1) /(1+\operatorname{Exp}(-1.5 \times(\operatorname{Lai}(n)-3))))
$$

Where:

Kmax : cultivar-dependent parameter

Potential crop transpiration $e o(n)$ is calculated using the classical crop coefficient approach applied to Penman-Monteith reference potential evapotranspiration $\operatorname{Etp}(n)$ :

$$
\text { Equation CELSIUS.25 }
$$

$$
e o(n)=\operatorname{Etp}(n) * K c(n)
$$

Potential crop transpiration eop(n) is calculated by subtracting potential evaporation to $e o(n)$, and accounting for an increase of up to $40 \%$ in the atmosphere's water demand at the vicinity of the crop when soil (and mulch) evaporation is low:

Equation CELSIUS.26

$$
\operatorname{eop}(n)=(\operatorname{eo}(n)-\operatorname{EoSM}(n)) \times(1.4-(0.4 \times(\operatorname{Esol}(n)+\operatorname{Emulch}(n)) / \operatorname{EoSM})
$$


Actual transpiration is reduced by the fraction of transpirable soil water following the

2 approach of Allen et al. (1998) as follows:

$$
\begin{gathered}
\text { If } \operatorname{WCrac}(n) \geq 0.7 \text { then Transpi }(n)=\operatorname{eop}(n) \\
\text { if } \operatorname{WCrac}(n)<0.7 \text { then Transpi }(n)=\operatorname{eop}(n) \times W \operatorname{Wrac}(n) / 0.7
\end{gathered}
$$

\section{Stress calculations}

6

\subsection{Nitrogen constraint}

See PlantClass. stressAzoteOld in the software code

A nitrogen limiting coefficient is calculated as follows:

Equation CELSIUS.28

$$
N L C=\operatorname{Min}\left[1 ; \alpha *\left(N_{\text {soil }}+N_{\text {inorg }}+N_{\text {org }}+N_{\text {symb }}\right) / I_{\text {fertmax }}\right]
$$

Where:

$N_{\text {soil }}, N_{\text {inorg }}, N_{\text {org }}$, and $N_{\text {symb }}$ are the mineral nitrogen amounts available to crops from, respectively, soil organic matter mineralization, inorganic fertilization, mineralized $\mathrm{N}$ from organic fertilization, and symbiotic fixation of atmospheric $\mathrm{N}$ by leguminous crops

$I_{\text {fertmax }}$ is the level of nitrogen supply above which growth is not limited, $\alpha$ a calibration coefficient (less than 1 ) accounting for losses of mineral $\mathrm{N}$ through volatilization and leaching.

5.2 Temperature stress applied to biomass growth

See PlanteClass.Biomasse in the software code

Equation taken from STICS

Equation CELSIUS.29 


$$
\begin{aligned}
& \text { If } \operatorname{Tm}(n)<\text { Tcopt then Ftemp }(n)=1-\left(\frac{\operatorname{Tm}(n)-t \text { copt }}{\text { tcmin }- \text { tcopt }}\right)^{2} \\
& \text { If } \operatorname{Tm}(n) \geq \text { Tcopt then Ftemp }(n)=1-\left(\frac{\operatorname{Tm}(n)-t c o p t}{\text { tcmax }-t c o p t}\right)^{2}
\end{aligned}
$$

1

2

Tcmin, tcopt, tcmax: cultivar-dependent parameters, respectively the minimal, optimal and maximal air temperatures for light to biomass conversion efficiency

\subsection{Water stress}

See PlanteClass. Calcule_LAl_SemiAride and PlanteClass.Biomass in the software code

Water stress reducing biomass growth (WSfactBio(n)) and LAI growth (WSFactLAI(n) a day $n$ are calculated using the respective thresholds WSBioT and WSLaiT of the reduction of the fraction of available soil water above which growth is reduced relatively to potential, as follows:

Equation CELSIUS.30:

$$
\text { if } \operatorname{WCrac}(n) \geq(1-\operatorname{WSBioT}) \text { then } W \operatorname{SfactBio}(n)=1
$$

$$
\begin{aligned}
& \text { if } W \operatorname{Crac}(n)<(1-W S B i o T) \text { then } W S f a c t B i o(n)=W \operatorname{Crac}(n) /(1-W S B i o T) \\
& \text { if } \operatorname{WCrac}(n) \geq(1-W S L a i T) \text { then } W S f a c t L a i(n)=1 \\
& \text { if } \operatorname{WCrac}(n)<(1-W S L a i T) \text { then } W S f a c t L a i(n)=W \operatorname{Crac}(n) /(1-W S L a i T)
\end{aligned}
$$

5.4 Interactions between water and nitrogen stresses.

See PlanteClass. Calcule_LAI_SemiAride and PlanteClass.Biomass in the software code

The stress factors LAIStress $(n)$ and BiomStress $(n)$ reducing growth in LAl and aboveground biomass (equations 3 and 6 ) respectively are calculated as follows:

Equation CELSIUS.31

$$
\begin{gathered}
\operatorname{LAIStress}(n)=\operatorname{Min}(\text { WSfactLai }(n) ; N L C) \\
\operatorname{BiomStress}(n)=\operatorname{Min}(\operatorname{WSfactBio}(n) ; N L C)
\end{gathered}
$$


Part III. Details about model calibration and test

CELSIUS involves a number of empirical parameters, a majority of which are cultivar-dependent, that had to be estimated by calibrating the model against measurements of key variables controlled by these parameters.

The data set used for calibration and test was the data set of millet plots detailed in Affholder (1997), plus data of groundnut plots from the ESPACE-PRODCLIM database (Forest and Cortier, 1989) and data of maize plots under the savannah environment of the Cerrado region of Brazil, as presented in Affholder et al (2003) and Affholder et al (2013). The soil water balance model as well as the sowing and emergence model, and their calibration parameters, were taken almost unchanged from Sarra-millet that provided reliable predictions of soil moisture and date chosen by farmers for sowing as depending on the rainfall sequence (Affholder, 1997). Readers may therefore refer to this publication for details about calibration and test of these components.

Cultivar and species dependent parameters relative to growth and development under non nitrogen limited environment of millet cultivar 'Souna3', the cultivar most commonly grown in Senegal, were taken unchanged from Affholder et al (2013). This also applied to species dependent parameters relative to maize. Readers interested to specific values and the literature sources in which they were found may refer to that article.

Two groundnut cultivars had to be considered, each for one of the two subzones of the study, namely the cultivars 55-437 and 73-33, used respectively in the Sine and Saloum zones. Species dependent parameters were taken from the literature (table C1). Thermal time development constants of these cultivars were obtained by summing thermal time over the corresponding observed dates of beginning and end of the key phenological stages as recorded in plots of the ESPACE database. Cultivar-dependent parameters of groundnut were calibrated using the same principle as in Affholder et al, (2013), and notably parameters Cgrain and CgrainVo were estimated for each cultivar by fitting the simulated number of grains to the boundary line of observed Ngrain plotted against simulated Vitmoy, for the whole set of groundnut plots in the database and setting the model for PYE calculation (i.e. with nitrogen stress not accounted for).

Except for thermal time constants, too few data were available in our database for calibrating with the same method as above the cultivar dependent parameters of maize for cultivar Noor96. We instead adapted the parameters of a cultivar used in family farms of Brazil, for which PYE had been

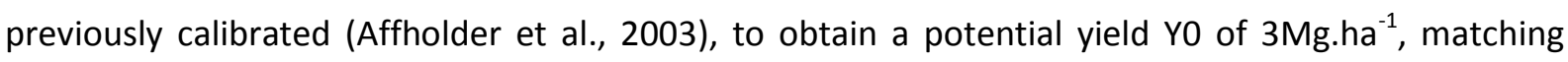
with the potential yield claimed in the technical leaflet provided with seeds of that cultivar. 
The parameters relative to nitrogen limitations (Nsymb, Ifertmax/ $\alpha$ ) were set so that the maximum and median values of simulated AGBwn and Ywn, over the set of historical weather data of each of the two Sine and Saloum subzones, was equal to the maximum and median observed value in the database for the species and crop management considered, for each of the following crop management types: MilExt on bushfield, MilManu on bushfield, MilManu on homefield, GroundExt on bushfield, GroundManu on bushfield (see table C1 on main text for characteristics of the cropping systems).

Figure C1 shows a final comparison, after calibration of CELSIUS, between simulated and observed yield for Millet, using the same data set as in the validation of SarraMillet (Affholder, 1997) with the exception of 12 plots (over 89) from a village in the north of the millet production area, for which rainfall data have been lost. With this plot sample for which Nitrogen amounts brought by organic and inorganic fertilization as well as organic $\mathrm{N}$ stocks in soils had been estimated in each plot, the model shows a relatively good capacity to predict the impact of nitrogen inputs and varying water stress on millet yield, as also denoted by the relatively satisfactory values of the Relative Root Mean Square of Error (RRMSE) and of model efficiency (ME), of respectively $27 \%$ and 0.68 .

Table C1: Species dependent parameters taken from the literature for simulation of groundnut. See Affholder et al, 2013 for parameters relative to Millet and Maize.

\begin{tabular}{llll}
\hline & Value & Unit & References \\
\hline tdmin & 10 & ${ }^{\circ} \mathrm{C}$ & (Leong and Ong, 1983; Mohamed et al., 1988; Bell \\
tdmax & 45 & ${ }^{\circ} \mathrm{C}$ & and Wright, 1998; Caliskan et al., 2008) \\
tcmin & 10 & ${ }^{\circ} \mathrm{C}$ & \\
tcmax & 45 & ${ }^{\circ} \mathrm{C}$ & \\
tcopt & 32 & ${ }^{\circ} \mathrm{C}$ & \\
\hline Ebmax & 2.6 & & (Sarr et al., 2004; Clavel et al., 2005; Kiniry et al., \\
kext & 0.62 & & 2005) \\
HImax & 0.47 & & \\
LAlmax & 6 & & \\
\hline Zracmax & 170 & $\mathrm{~cm}$ & (Allen et al., 1998; Collino et al., 2000; Collino et al., \\
Kmax & 1.2 & & 2001; Dardanelli et al., 2004; Sarr et al., 2004) \\
\hline
\end{tabular}




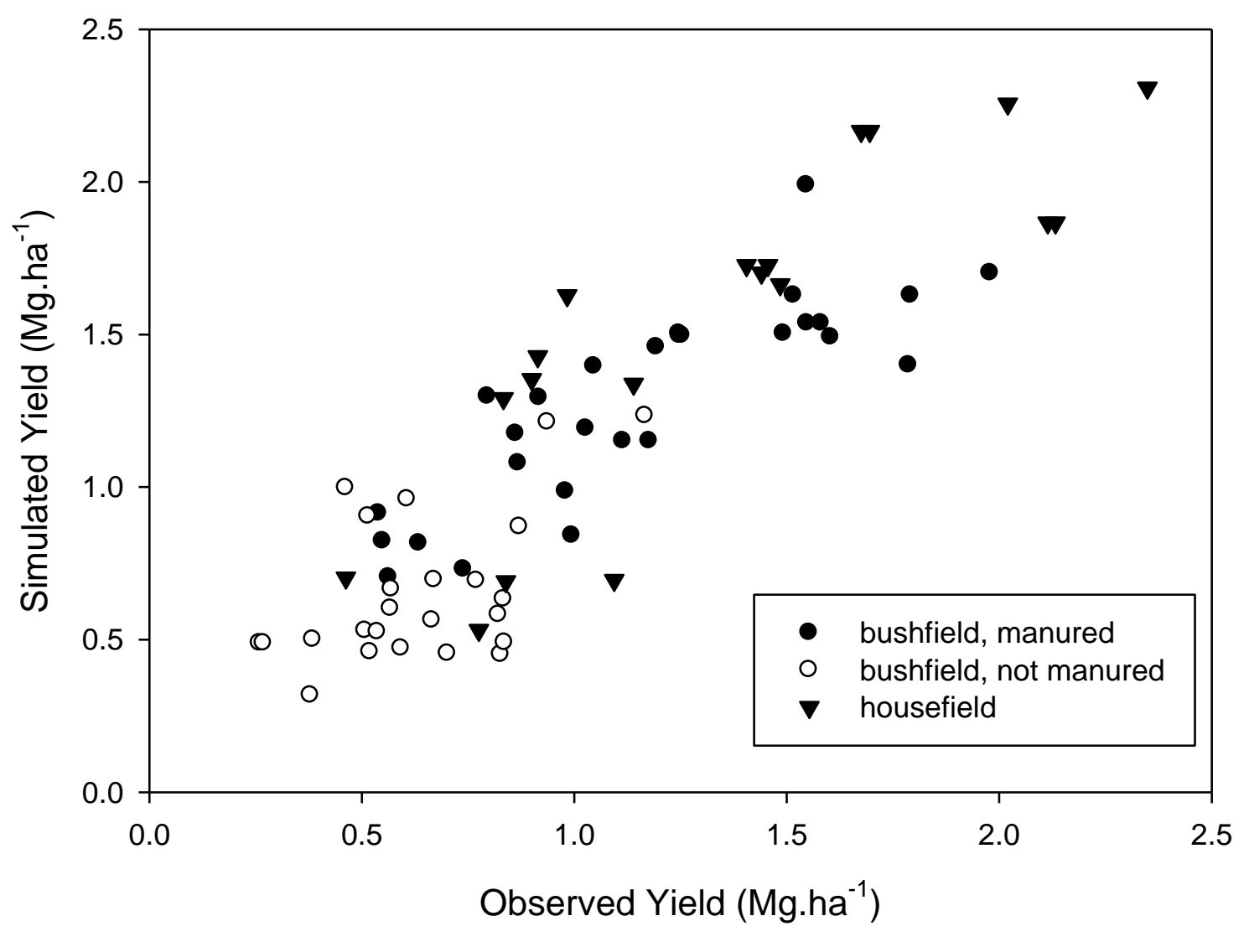

3 


\section{Appendix D. ANDERS-CELCIUS model calibration and evaluation}

We used time-series observations of local monthly product prices to simulate price distributions. We first calculated the average price at harvest over the period 2008-2012. We also estimated the standard deviation and correlation matrix of the crop prices over the period 19962012. We then performed Latin-Hypercube sampling using the method described in Richardson et al. (2000) to generate 20 equi-probable states of nature relative to prices and taking into account the correlations between the prices of products.

The parameters used to calibrate the model were the absolute risk aversion $\left(r_{a}\right)$ and transaction cost coefficients, the latter defined as the gap between the selling and the purchase output prices at the farm gate. The values of risk aversion and transaction costs were assigned so as to minimize the deviation between the observed and the simulated farm operational plan (cropping system and animal fattening). While the values of transaction costs were assigned per subzone, the values of the absolute risk aversion were calibrated for each farm, according to their own initial wealth, but the same relative risk aversion were assigned to all farm-types. The relationship between the absolute risk aversion $\left(r_{a}\right)$ and the relative risk aversion $\left(r_{r}\right)$ is given as follows (Hardaker et al., 2004):

$$
r_{a}=\frac{r_{r}}{W}
$$

To calculate $r_{a}$ we thus first assessed the initial wealth for each simulated farm using as proxies the number of seeders, hoes, plows and carts, and the herd size (cattle, draught animal). The values and the corresponding levels of risk aversion are given in Table D1. The calibration led to a value of the relative risk aversion equal to 2 for all the types which is a reasonable level according to the literature. For example, Hardaker et al. (2004) proposed a classification where the coefficients range from 0 (risk neutral) to 4 (extremely risk averse) with values of 2 referring to rather risk averse farmers. Recently, De Nicola (2015a) estimated a risk aversion coefficient of 2.67 for Malawian farmers while the estimates by Charness and Viceisza (2012) for Senegalese farmers correspond to a coefficient of 1.39, according to calculations by De Nicola (2015b). Transactions costs depend on the crop and their highest level reach 1.17 in the Sine subzone and 1.13 in the Saloum subzone. 
Table D1. Values of the initial wealth and the levels of risk aversion

\begin{tabular}{lllll}
\hline & Sine1 & Sine2 & Saloum1 & Saloum2 \\
\hline Initial wealth (FCFA) & 700000 & 1800000 & 800000 & 2000000 \\
Relative risk aversion $\left(r_{r}\right)$ & 2 & 2 & 2 & 2 \\
Absolute risk aversion $\left(r_{a}\right)$ & 0.0000028 & 0.0000011 & 0.0000025 & 0.000001 \\
\hline
\end{tabular}

2

3

4

5

6

7

\begin{tabular}{lccccccccc} 
Table D2: comparison between observed and simulated farm operational plan (crop mix) \\
& \multicolumn{2}{c}{ Sine1 } & \multicolumn{2}{c}{ Sine2 } & \multicolumn{2}{c}{ Saloum1 } & \multicolumn{2}{c}{ Saloum2 } \\
& Obs & Sim & Obs & Sim & Obs & Sim & Obs & Sim \\
& 1.91 & 1.81 & 5.66 & 5.75 & 3.73 & 3.8 & 7.47 & 8.01 \\
Millet (ha) & 0.06 & 0.07 & 0 & 0 & 0.59 & 0.34 & 2.16 & 1.7 \\
Maize (ha) & 1.53 & 1.62 & 4.84 & 4.75 & 2.18 & 2.35 & 5.57 & 5.49 \\
Groundnut (ha) & 1.14 & 1.17 & 4.01 & 3.67 & 2.48 & 2.18 & 4.86 & 3.57 \\
\hline Manure application (ha) & 0.5 & 0.4 & 1.9 & 1.6 & & & n/a & \\
\hline Head of cows for fattening & 3.3 & 0 & 5 & 4.8 & 0.2 & 0 & 0.5 & 0.8 \\
Head of sheep for fattening & & & & & & & & \\
\hline
\end{tabular}
acceptable.

The model shows a good level of consistency between observed production choices and those simulated in the baseline scenario (i.e. without any insurance or subsidy program). At the aggregated level of crops, it reproduces the quasi-absence of maize in the Sine farm-types (present in a marginal proportion in Sine1) and its presence in the Saloum farm-types (Table D2). Furthermore, the simulated hierarchy among the three crops (crop mix) corresponds to the observations in every farmtype. We also observe that the total amount of manure produced through animal husbandry is close to the observed figure (as indicated by the total area dedicated to manure-based cropping systems). Also, if the number of animal for fattening is slightly under-estimated for Sine, values obtained are

14

At the cropping system level, the same cropping systems (extensive and manure-based millet, extensive groundnut and, in Saloum, fertilized maize) dominate in both observations and simulations (Fig. D1). 

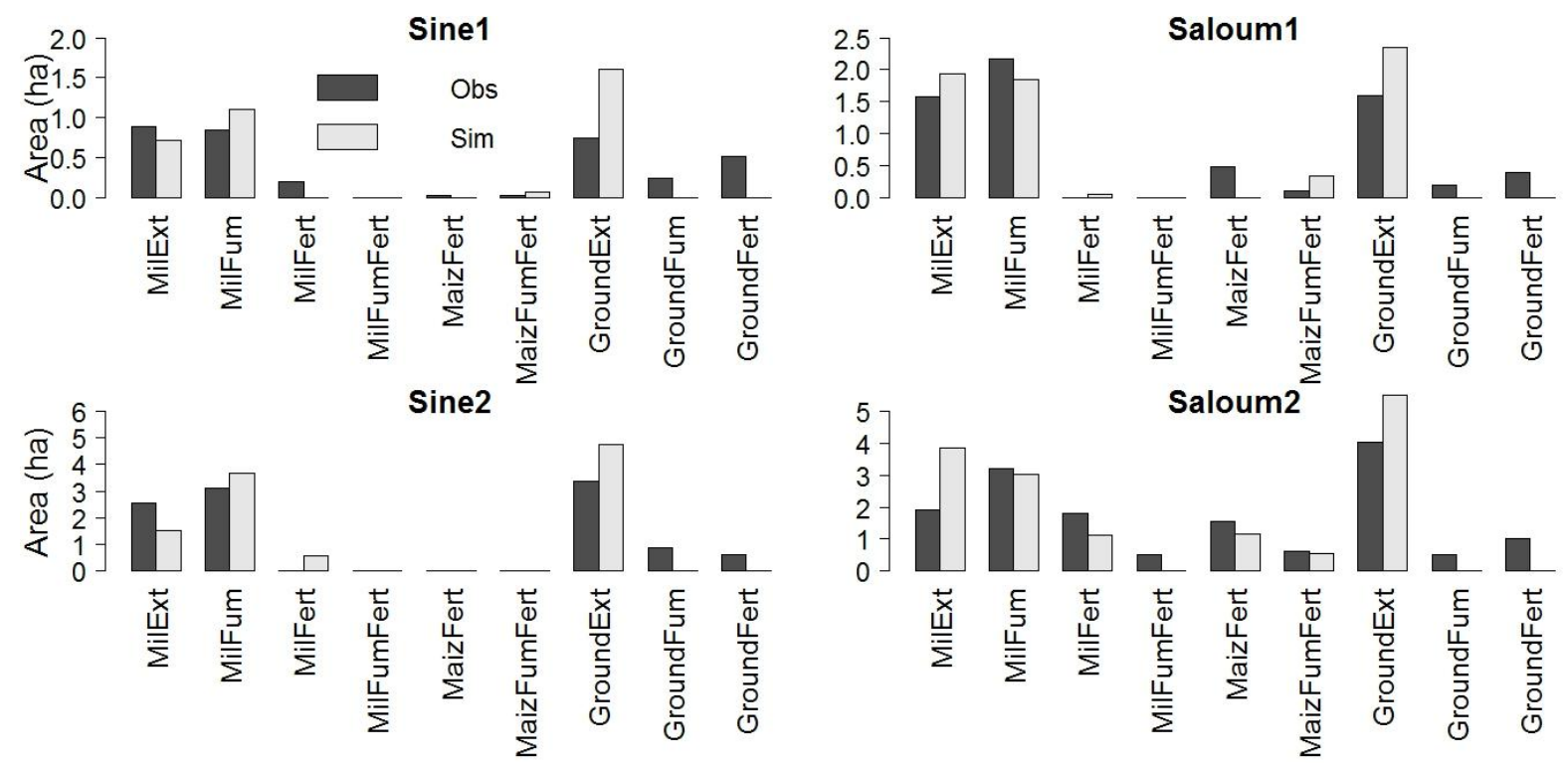

Fig. D1: comparison between observed (Obs) and simulated (Sim) land allocation across crops and cropping systems.

The main discrepancies between the observed results and the simulations bear on the slight but systematic overestimation of extensive groundnut and a concomitant underestimation of intensive groundnut compared to observations. Interviews with farmers and local experts regarding this point suggest that the typical practice is closer to the predictions of the model than to what was observed during our farm survey of 2012. The expectancies of farmers, at sowing time, regarding the selling price of groundnut at harvest, may some years be strongly influenced by the government's communication encouraging farmers to invest more in groundnut, leading to cultivation choices that may slightly differ from what would be expected from prices expectancies based on series of past observed prices as in our model. Nevertheless, in the observed farms, whatever the subzone and farm-type, areas cropped with extensive groundnut clearly overcome the areas with more intensive groundnut, and this is well captured by the baseline simulation. 


\section{Appendix E. Distribution of gross margins for each cropping system}

Fig. E1 shows the whole distribution of gross margins (GM) for each cropping system. GMs are defined here as the difference between the stochastic total value of production (yield times unit price) and the production costs. Production costs include only the costs of seeds and chemical inputs. Neither the labor costs nor the value of the manure nutrients have been included in these cumulative distribution functions since the opportunity cost of family labor and the cost of manure produced on the farm vary between seasons. We observe that extensive cropping systems (i.e. without any use of inorganic fertilizer or manure) give less risky distributions than more intensive cropping systems (i.e. requiring inorganic fertilizer and/or manure). As an example in about $15 \%$ of the states of nature, the extra yield of millet obtained from inorganic fertilizer application cannot compensate for the cost of purchasing the fertilizer. This result is in accordance with well-known results from previous research reporting the risk-increasing property of crop intensification (Affholder, 1997; Rötter and van Keulen, 1997). The distribution of manure-based cropping system yields is also flatter. Note that the dominance of manure-based cropping systems over the extensive cropping system could result from not taking into account direct and indirect costs of farm manure in GM calculations. However, in the ANDERS model (and in the real world), the management of manure does involve labor input so that the risk at the field scale of a low yield obtained with manure application in the driest years may translate into economic risk at the farm scale. Moreover, the yield risk related to intensification is much higher in the Sine subzone, where the climate is drier than in Saloum. This risk is also higher for maize than for millet. The groundnut GM distributions indicate that fertilizer-based cropping systems are not much economically profitable since in about $60 \%$ and $80 \%$ of the states of nature (in the Sine and the Saloum subzones, respectively), extensive cropping systems give higher GM. 

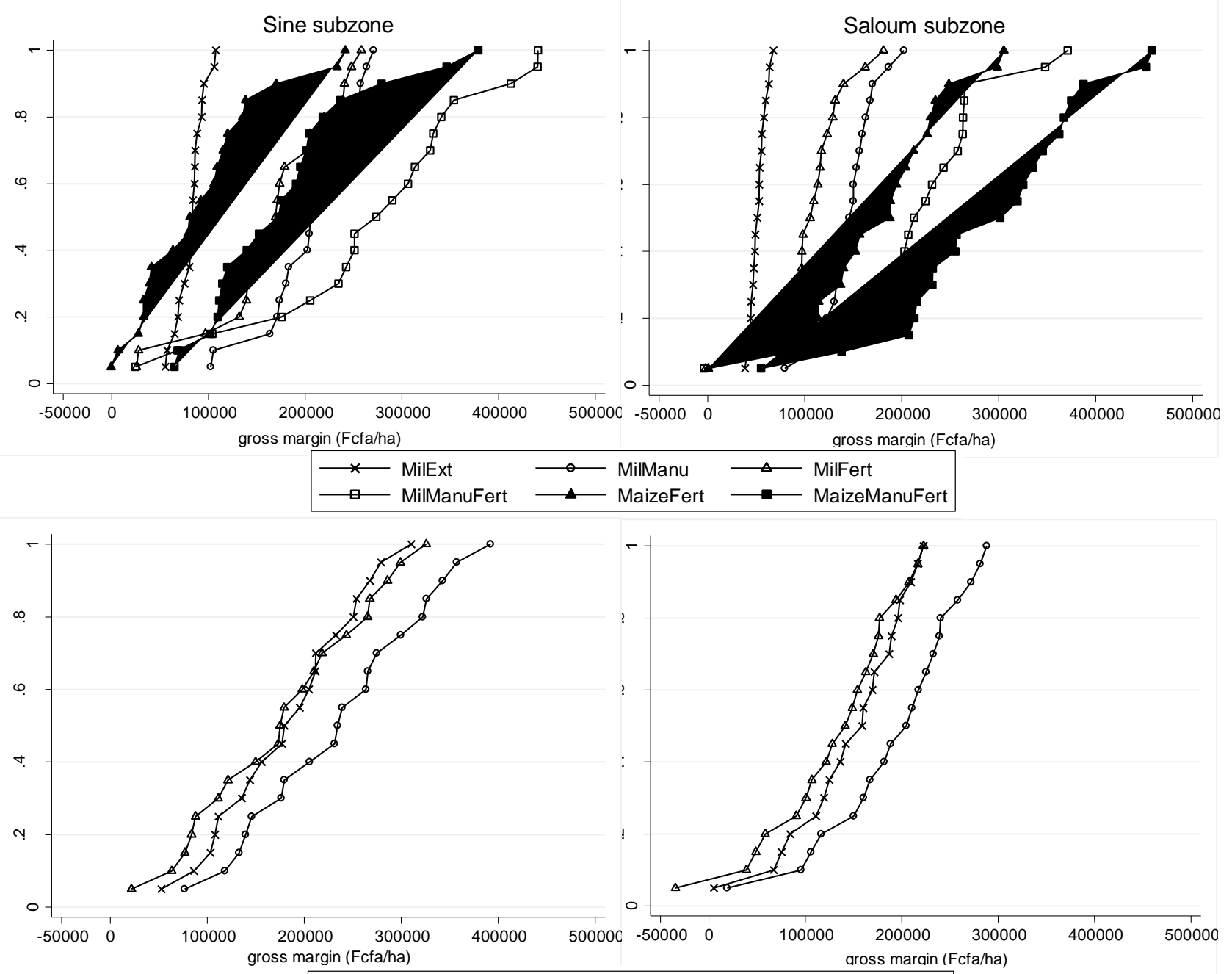
$\longrightarrow$ GroundnutExt $\longrightarrow$ GroundnutManu $\longrightarrow$ GroundnutFert

Fig. E1: Cumulative distribution functions of gross margins for cereals (millet and maize) and groundnut cropping systems 


\section{Appendix F: The bioeconomic ANDERS model}

1. Sets:

$a c$ : agricultural activities

ag: age of family members

an: animal types,

$e$ : state of nature

ge: gender of family members

inp: inputs

ins: insurance type

ne: nutrient type (digestible nitrogen matter / energy in kcal)

$p$ : period

$p d t$ : agricultural products

$s$ : soil types,

sps: subsidy program scenario

str: straw type (from millet or maize; subset of pdt for straw)

$t$ : type of off-farm labor (including agricultural and non-agricultural labor, remittances)

tan: animals used for traction (subset of an)

$z$ : field types

\section{Variables}

\section{Endogenous variables are in UPPER CASE and exogenous parameters in lower case}

$\pi_{e}$ income by state of nature

activ $_{g e, a g}$ active family members by gender and age

anim $_{a n, p}$ stock of animals by type of animal and period

animneed $_{n e, p}$ animals nutritional needs (ne) by period

atneed $_{z, s, a c, p}$ animal traction requirements by field type, soil type, agricultural activity and period $B A_{a n, p}$ animals bought by type of animal and period

$B C_{p d t, p, e}$ agricultural products bought for consumption

$B R W_{p}$ borrowing by period

$\mathrm{CASH}_{p, e}$ Cash available by period $\mathrm{p}$ and state of nature

cashtr $_{\text {sps }}$ Cash transfer by subsidy program scenario

canim $_{\text {an }}$ return from animal selling by animal type

$\mathrm{Co}_{s, z, a c, \text { inp, } p}$ input coefficient for agricultural activities by animal type by field type, soil type, agricultural activity, input and period

coanim $_{\text {an }}$ costs associated with raising animals by animal type

$\operatorname{CONSA}_{p, p d t, e}$ animal consumption of farm products by period, product and state of nature

CONSAT $T_{p, p d t, e}$ Total animal consumption by period, product and state of nature

$\mathrm{CONSH}_{p, p d t, e}$ human consumption of agricultural products by period, product and state of nature $\mathrm{CONSO}_{p, p d t, e}$ Other consumption of farm products by period, product and state of nature (straw) cont $f_{\text {ne }} \quad$ Nutritional content of purchased feedstock by nutrient type contpa $_{n e, p}$ Nutritional content of pasturing by nutrient type and period contpd $t_{n e}$ Nutritional content of straw by nutrient type $F E E D_{a n}$ feedstock bought for animals by animal type FINCASH $\mathrm{H}_{e}$ Cash available at the end of the year, by state of nature FINSTOCKAC $C_{p d t, e}$ agricultural product stocks at the end of the year by product and state of nature human $_{a g, g e}$ family members by age and gender 
$i$ interest rate

inicash initial cash

inistock $_{p d t}$ initial stock by agricultural product

isubv $v_{s p s}$ subsidy on interest rate by subsidy program scenario

inpsubs $_{\text {sps }}$ subsidy on inputs price by subsidy program scenario

inssubs $_{s p s}$ subsidy on insurance premium by subsidy program scenario

INSX $X_{a c, i n s}$ insured area cultivated by activity and insurance type

$k_{c a l}$ pdt Energy (in kcal) contained in each product, by product

9 kcalneed $_{g e, a g, p}$ Energy (in kcal) necessary to feed households members by gender, age and period

$L a b_{a c, p}$ labor need by agricultural activity and period

land $_{s, z}$ farm endowment in land by type and zone

manuprod $_{\text {an }}$ manure production by animal type

minc $_{p}$ minimum expenditure in cash for the household by period

$O F F_{t, p}$ off farm activities by type of off-farm labor and period

pac $p d t, p, e$ crop buying prices by product, period and state of nature

panim $_{a n, p}$ animal prices by type of animals and period

past $_{p, e}$ feed from pasture by period and state of nature

Pastarea $_{p}$ pasture Area by period

$P A Y O F F_{a c, i n s, e}$ Payoff associated with insurance by agricultural activity, insurance type and state of nature

pco $_{\text {inp }, p}$ inputs prices by input and period

pfeed $_{\text {an }}$ feed price by animal type

pinsu ${ }_{a c, i n s}$ Insurance premium by agricultural activity and insurance type

pvac pdt,p,e crop selling prices by product, period and state of nature

$p w x_{p}$ agricultural labor price by period

$r a$ absolute risk aversion

$R E N T A_{p}$ rented animals for traction by period

$S A_{a n}$ animals sold by animal type

$S C_{p d t, p, e}$ crops sold by product, period and state of nature

$S T O C K A C_{p d t, p, e}$ agricultural product stocks by product, period and state of nature

strawstr,e coefficient for straw used for manure by straw type and state of nature

tracd $_{\text {tan,p }}$ days of traction by animal type and period

$w$ initial wealth

$w d_{g e, a g, p}$ working days by gender, age and period

$W F A M_{p}$ family labor used on farm by period

$W X_{p}$ agricultural labor bought by period

$X_{s, z, a c}$ area cultivated by soil type, field type and agricultural activity

$Y_{s, z, a c, p d t, e}$ yield by animal type by soil type, field type, agricultural activity, product and state of nature YPast $_{p, e}$ pasture capacity by period and state of nature 


\section{Equations}

Objective function

$E U=\frac{1}{n} \sum_{e=1}^{n} 1-\operatorname{Exp}\left[-r_{a}\left(\pi_{e}+w\right)\right]$

Certainty equivalent income

$C E I=\frac{\ln [1-E U]}{-r_{a}}-w$

\section{Income}

$\pi_{e}=\sum_{p, p d t}\left(\sum_{a c, s, z}\left(X_{s, z, a c}{ }^{*} y i e l d_{s, z, a c, p d t, e}\right)-\operatorname{CONSA}_{p, p d t, e}-\operatorname{CONSO}_{p, p d t, e}\right) * p v a c p d t, p, e-\sum_{i n p, p} \sum_{s, z, a c} X_{s, z, a c} *$ $c o_{s, z, a c, i n p, p} * p c o_{i n p, p} *\left(1-\right.$ inpsubs $\left._{i n p, s p s}\right)-\sum_{p} W X_{p} * p w x_{p}-\sum_{a c, i n s} \quad$ pinsu $_{a c, i n s} *\left(1-\right.$ inssubs $\left._{s p s}\right) *$ $I N S X_{a c, i n s}+P A Y O F F_{a c, i n s, e} * I N S X_{a c, i n s}$

$+\sum_{p, a n}\left(\operatorname{canim}_{a n}-\operatorname{coanim}_{a n}-F E E D_{a n} *\right.$ pfeed $\left._{a n}\right) *\left(\operatorname{anim}_{a n, p}+B A_{a n, p}-S A_{a n, p}\right)+\left(B A_{a n, p}-S A_{a n, p}\right) *$

panim $_{a n, p}+\left(\operatorname{anim}_{a n, " p 7^{\prime \prime}}-S A_{a n, " p 7^{\prime \prime}}\right) *$ panim $_{a n, p}+\sum_{t, p} O F F_{t, p}+\sum_{s p s} \operatorname{cashtr}_{s p s}-\sum_{p} \quad i *\left(1-i s u b s_{s p s}\right) * B R W_{p}(\mathrm{~F} 2)$

Land constraint

$\sum_{a c} X_{s, z, a c} \leq \operatorname{land}_{s, z}$

Labor needs

$\sum_{s, z, a c} X_{s, z, a c} * l a b_{s, a c, p}+\sum_{a n}\left(\operatorname{anim}_{a n, p}+B A_{a n, p}-S A_{a n, p}\right) * l a b_{a n, p}+\sum_{t} O F F_{t, p} \leq W F A M_{p}+$ $W X_{p}$

\section{Labor constraint}

$W F A M_{p}+\sum_{t} O F F_{t, p} \leq \sum_{g e, a g} a c t i v_{g e, a g} * w d_{g e, a g, p}$

Animal traction constraint

$\sum_{s, z, a c} X_{s, z, a c} *$ atneed $_{s, z, a c, p}-$ RENTA $_{p} \leq \sum_{\text {tan }}$ anim $_{\text {tan }} * \operatorname{tracd}_{\text {tan }, p}$

Cash equations

$\mathrm{CASH}_{p, e} \geq 0$

For $\mathrm{p} \geq 1$ :

$\mathrm{CASH}_{p, e}=\mathrm{CASH}_{p-1, e}+\sum_{p d t} S C_{p d t, p-1} * \operatorname{pvac}_{p d t, p-1, e}$

$-\sum_{\text {inp }} \sum_{s, z, a c} X_{s, z, a c} * c o_{s, z, a c, i n p, p-1} * p c o_{\text {inp }, p-1} *\left(1-\right.$ inpsubs $\left._{\text {inp }, \text { sps }}\right)$

$-W X_{p-1} * p w x_{p-1}-R E N T A * \operatorname{Pra}$

$+\sum_{a n}\left(\right.$ Canim $_{a n}-$ coanim $_{a n}-F E E D_{a n} *$ pfeed $\left._{a n}\right) *\left(\operatorname{anim}_{a n, p-1}-S A_{a n, p-1}+B A_{a n, p-1}\right)$

$+\left(S A_{a n, p-1}-B A_{a n, p-1}\right) *$ panim $_{a n, p-1}-\sum_{p d t} B C_{p-1, p d t, e} * p a c_{p-1, p d t, e}$

$+\sum_{t} O F F_{t, p-1}+B R W_{p-1}-\operatorname{minc}_{p-1}$

- if $(P=3) \quad \sum_{a c, i n s}$ pinsu $u_{a c, i n s} *\left(1-\right.$ inssubs $\left._{s p s}\right) * I N S X_{a c, i n s}+$ cashtr $_{s p s}$

+ if $(P=6) \quad P A Y O F F_{a c, i n s} * I N S X_{a c, i n s}$

Final cash

FINCASH $_{e}=$ CASH" $7^{\prime \prime}, e$

$$
\begin{aligned}
& +\sum_{p d t} S C_{p d t, " P 7^{\prime}} * p v a c_{p d t, " P 7 "}+\sum_{a n} S A_{a n, " P 7^{\prime \prime}} * \operatorname{panim}_{a n, " P 7 "}-\sum_{p d t} B C_{" P 7 ", p d t, e} * p a c_{\text {"PP",pdt,e }} \\
& -\sum_{p} B R W_{p} *\left(1+i\left(1-i s u b s_{s p s}\right)\right)
\end{aligned}
$$

Supply-utilization account for $p \geq 1$ : 
$2 S_{\text {TOCKAC }}$ pdt,p,e $=S T O C K A C_{p d t, p-1, e}$

$3+B C_{p d t, p-1, e}-S C_{p d t, p-1, e}-\operatorname{CONSAT}_{p-1, p d t, e}-\mathrm{CONSH}_{p-1, p d t, e}-\mathrm{CONSO}_{p-1, p d t, e}$

$4+i f(P=P 6) \quad \sum_{a c, s, z,} X_{s, z, a c}{ }^{*} y^{*}{ }^{2}{ }^{2} d_{s, z, a c, p d t, e}$

Final stocks

FINSTOCKAC $_{p d t, e}=S T O C K A C_{p d t, " P 7^{\prime,}, e}+B C_{p d t, " P 7^{\prime, e}}-S C_{p d t, " P 7^{\prime, e}}$

Family nutritional constraint

$\sum_{g e, a g} k_{\text {kcalneed }}$ ge,ag,p $*$ human $_{g e, a g} \leq \sum_{p d t} k_{c a l}{ }_{p d t} * \mathrm{CONSH}_{p, p d t, e}$

Animals nutritional constraint $\operatorname{CONSAT}_{p, p d t, e}+\sum_{a n} \operatorname{cont}_{\text {ne }} * F E E D_{\text {an }}$

Pasture capacity constraint

past $_{p, e} \leq$ Pastarea $_{p} *$ YPast $_{p, e}$

Manure production

$\sum_{a n}\left(\operatorname{anim}_{a n, p}+B A_{a n, p}-S A_{a n, p}\right) \quad a_{a n} * \operatorname{manuprod}_{a n} * \operatorname{straw}_{s t r, e}=$ CONSO $_{p, s t r, e}$

Manure balance

$\sum_{p} \sum_{s, z, a c} X_{S, z, a c} * c o_{s, z, a c, " m a n ", p} \leq \sum_{a n}\left({ }_{n}\left(\operatorname{anim}_{a n, p}+B A_{a n, p}-S A_{a n, p}\right) * \operatorname{manuprod}_{a n}\right.$

Viability constraint on expected cash

inicash $\leq \frac{1}{n} \sum_{e=1}^{n}$ FINCASH $_{e}$

Viability constraint on expected energy (in kcal) for stocks

$\sum_{\mathrm{pdt}}$ inistock $_{p d t} *$ kcal $_{p d t} \leq \frac{1}{n} \sum_{e=1}^{n} \sum_{\mathrm{pdt}}$ FINSTOCKAC $_{p d t, e} * k c a l_{p d t}$

Viability constraint on cash (softened by informal insurance)

$0.5 *$ inicash $_{e} \leq$ FINCASH $_{e}$

Viability constraint on stocks (softened by informal insurance)

$0.5 * \sum_{\mathrm{pdt}}$ inistock $_{p d t, e} *$ kcal $_{p d t} \leq \sum_{\mathrm{pdt}}$ FINSTOCKAC $_{p d t, e} *$ kcal $_{p d t}$

$\sum_{a n}$ animneed $_{a n, n e, p} *\left(\operatorname{anim}_{a n, p}+B A_{a n, p}-S A_{a n, p}\right) \leq \operatorname{contpa}_{n e, p} *$ past $_{p, e}+\sum_{p d t} \operatorname{contpdt}_{n e} *$ 
Affholder, F., 1995. Effect of organic matter input on the water balance and yield of millet under tropical dryland condition. Field Crops Res. 41, 109-121.

Affholder, F., 1997. Empirically modelling the interaction between intensification and climatic risk in semiarid regions. Field Crops Res. 52, 79-93.

Affholder, F., Poeydebat, C., Corbeels, M., Scopel, E., Tittonell, P., 2013. The yield gap of major food crops in family agriculture in the tropics: Assessment and analysis through field surveys and modelling. Field Crops Res. 143, 106-118.

Affholder, F., Scopel, E., Madeira Neto, J., Capillon, A., 2003. Diagnosis of the productivity gap using a crop model. Methodology and case study of small-scale maize production in central Brazil. Agronomie 23, 305-325.

Affholder, F., Tittonell, P., Corbeels, M., Roux, S., Motisi, N., Tixier, P., Wery, J., 2012. Ad Hoc Modeling in Agronomy: What Have We Learned in the Last 15 Years? Agron. J. 104, 735-748.

Albergel, J., Perez, P., Vaskmann, M., 1991. Amélioration des modèles de bilan hydrique sur parcelle par la prise en considération des états de surface. In: Sivakumar, M.V.K., Wallace, J.S., Renard, C., Giroux, C. (Eds.), Soil water balance in the Sudano-Sahelian zone. Int. Assoc. of Hydrol. Sci., Niamey, Niger, pp. 483-496.

Allen, R.G., Pereira, L.S., Raes, D., Smith, M., 1998. Crop evapotranspiration: guidelines for computing crop water requirements. FAO Irrigation and Drainage Paper. Food and Agriculture Organization (FAO), Rome Italy, p. xxvi + 300 pp.

Bell, M.J., Wright, G.C., 1998. Groundnut growth and development in contrasting environments 2. Heat unit accumulation and photo-thermal effects on harvest index. Exp. Agric. 34, 113-124.

Brisson, N., Gary, C., Justes, E., Roche, R., Mary, B., Ripoche, D., Zimmer, D., Sierra, J., Bertuzzi, P., Burger, P., Bussière, F., Cabidoche, Y.M., Cellier, P., Debaeke, P., Gaudillère, J.P., Hénault, C., Maraux, F., Seguin, B., Sinoquet, H., 2003. An overview of the crop model STICS. Eur. J. Agron. 18, 309-332.

Brisson, N., Mary, B., Ripoche, D., Jeuffroy, M.H., Ruget, F., Nicoullaud, B., Gate, P., Devienne Barret, F., Antonioletti, R., Durr, C., Richard, G., Beaudoin, N., Recous, S., Tayot, X., Plenet, D., Cellier, P., Machet, J.M., Meynard, J.M., Delecolle, R., 1998. STICS: a generic model for the simulation of crops and their water and nitrogen balances. I. Theory and parameterization applied to wheat and corn. Agronomie 18, 311-346.

Caliskan, S., Caliskan, M.E., Arslan, M., Arioglu, H., 2008. Effects of sowing date and growth duration on growth and yield of groundnut in a Mediterranean-type environment in Turkey. Field Crops Res. 105, 131-140.

Casenave, A., Valentin, C., 1989. Les états de surface de la zone sahélienne. Influence sur I'infiltration. ORSTOM, Bondy, p. 202.

Casenave, A., Valentin, C., 1992. A runoff capability classification system based on surface features criteria in semi-arid areas of West Africa. Journal of Hydrology 130, 231-249.

Charness, G., \& Viceisza, A., 2012. Comprehension and risk elicitation in the field: Evidence from rural Senegal. Department of Economics, UC Santa Barbara 
Clavel, D., Drame, N.K., Roy-Macauley, H., Braconnier, S., Laffray, D., 2005. Analysis of early responses to drought associated with field drought adaptation in four Sahelian groundnut (Arachis hypogaea L.) cultivars. Environmental and Experimental Botany 54, 219-230.

Collino, D.J., Dardanelli, J.L., Sereno, R., Racca, R.W., 2000. Physiological responses of argentine peanut varieties to water stress. Water uptake and water use efficiency. Field Crops Res. 68, 133-142.

Collino, D.J., Dardanelli, J.L., Sereno, R., Racca, R.W., 2001. Physiological responses of argentine peanut varieties to water stress. Light interception, radiation use efficiency and partitioning of assimilates. Field Crops Res. 70, 177-184.

Dardanelli, J.L., Ritchie, J.T., Calmon, M., Andriani, J.M., Collino, D.J., 2004. An empirical model for root water uptake. Field Crops Res. 87, 59-71.

De Nicola, F., 2015a. The impact of weather insurance on consumption, investment, and welfare. Quantitative Economics 6, 637-661.

De Nicola, F., 2015b. Handling the Weather. Insurance, Savings, and Credit in West Africa. World Bank Policy Research Working Paper 7187.

Dingkuhn, M., Baron, C., Bonnal, V., Maraux, F., Sarr, B., Sultan, B., Clopes, A., Forest, F., 2003. Decision-support tools for rainfed crops in the Sahel at the plot and regional scales. In: StruifBontkes, T.E., Wopereis, M.C.S. (Eds.), A Practical Guide to Decision-support Tools for Agricultural Productivity and Soil Fertility Enhancement in Sub-Saharan Africa. IFDC, CTA, pp. 127-139.

Forest, F., Clopes, A., 1994. Contribution à l'explication de la variabilité du rendement d'une culture de maïs plus ou moins intensifiée à l'aide d'un modèle de bilan hydrique amélioré. In: Reyniers, F.N., Netoyo, L. (Eds.), Bilan hydrique agricole et sécheresse en Afrique tropicale. Vers une gestion des flux hydriques par les systèmes de culture ? (Actes Sem.. Int., Bamako, Mali, Decembre 1991). J. Libbey, Paris, pp. 3-15.

Forest, F., Cortier, B., 1989. Evaluation et suivi de la production agricole en fonction du climat et de I'environnement, ESPACE. CIRAD-IRAT, Montpellier, p. 203 p.

Hardaker, J.B., Huirne, R.B.M., Anderson, J.R., Lien, G., 2004. Coping with risk in agriculture. CAB International, Wallingford, UK.

Janssen, B.H., Guiking, F.C.T., van der Eijk, D., Smaling, E.M.A., Wolf, J., Reuler, H., 1990. A system for quantitative evaluation of the fertility of tropical soils. Geoderma 46, 299-318.

Kiniry, J.R., Simpson, C.E., Schubert, A.M., Reed, J.D., 2005. Peanut leaf area index, light interception, radiation use efficiency, and harvest index at three sites in Texas. Field Crops Res. 91, 297-306.

Leong, S.K., Ong, C.K., 1983. THE INFLUENCE OF TEMPERATURE AND SOIL-WATER DEFICIT ON THE DEVELOPMENT AND MORPHOLOGY OF GROUNDNUT (ARACHIS-HYPOGAEA L). J. Exp. Bot. 34, 15511561.

Luu Ngoc Quyen, 2012. Introduction d'une culture de printemps dans les systèmes de culture des "terres irrigables" des montagnes du Nord du Vietnam. Approche par modèle agroclimatique. Ph. D. Thesis Agronomie. Supagro, Montpellier, p. 152.

Mohamed, H.A., Clark, J.A., Ong, C.K., 1988. GENOTYPIC DIFFERENCES IN THE TEMPERATURE RESPONSES OF TROPICAL CROPS .2. SEEDLING EMERGENCE AND LEAF GROWTH OF GROUNDNUT (ARACHIS-HYPOGAEA L) AND PEARL-MILLET (PENNISETUM-TYPHOIDES S-AND-H). J. Exp. Bot. 39, 1129-1135. 
Richardson, J.W., Klose, S.L., Gray, A.W., 2000. An applied procedure for estimating and simulating multivariate empirical (MVE) probability distributions in farm-level risk assessment and policy analysis. J. Agr. Appl. Econ. 32, 299-316.

Rötter, R., van Keulen, H., 1997. Variations in yield reponse to fertilizer application in the tropics: risks and opportunities for smallholders cultivating maize on Kenya's arable land. Agricultural Systems 53, 69-95.

Sarr, B., Lecoeur, M., Clouvel, P., 2004. Irrigation scheduling of confectionery groundnut (Arachis hypogeaea L.) in Senegal using a simple water balance model. Agric. Water Manage. 67, 201-220.

Scopel, E., Macena da Silva, F.A., Corbeels, M., Affholder, F., Maraux, F., 2004. Modelling crop residue mulching effects on water use and production of maize under semi-arid and humid tropical conditions. Agronomie 24, 383-395.

Sissoko, F., 2009. Analyse des flux d'eau dans les systèmes de culture sous couverture végétale en zone soudano-sahélienne: cas du coton semé après une culture de sorgho/brachiaria au sud du Mali. Science du sol Agronomie. Supagro, Montpellier, p. 163.

Tittonell, P., Corbeels, M., van Wijk, M.T., Giller, K.E., 2010. FIELD-A summary simulation model of the soil-crop system to analyse long-term resource interactions and use efficiencies at farm scale. Eur. J. Agron. 32, 10-21.

Van Ittersum, M.K., Cassman, K.G., Grassini, P., Wolf, J., Tittonell, P., Hochman, Z., 2013. Yield gap analysis with local to global relevance-A review. Field Crops Res. 143, 4-17.

Van Ittersum, M.K., Rabbinge, R., 1997. Concepts in production ecology for analysis and quantification of agricultural input-output combinations. Field Crops Res. 52, 197-208.

Van Keulen, H., 1975. Simulation of water use and herbage growth in arid regions. PUDOC, Wageningen, The Netherlands. 